\title{
A Comparative Study of Different Automated Teller Machine and Its Effectiveness Based on Customer's Satisfaction
}

\author{
Marianne B. Calayag, PIE, Donna Maryeliz M. Regala, \\ Camile Jocelle R. Rivera and Danielle Mikee N. Tancio
}

College of Engineering, Bulacan State University, Malolos, Bulacan, Philippines

E-mail: \{donna.mregala; tancio.danielle\}@gmail.com;

camilejocelle@yahoo.com

Received 29 December 2016; Accepted 18 May 2017;

Publication 3 June 2017

\begin{abstract}
Research on human-computer interaction started in the year 1960s. It was supported by different fields such as anthropology, cognitive psychology, cognitive science, experimental psychology, ergonomics and human factors. Even though there are almost, millions of automatic teller machines available in the world, users of the machine still have usability problems including inappropriate user - ATM interaction, display problems and others. The study aims to conduct a comparative study between five different automated teller machines; Landbank of the Philippines, Bank of the Philippine Islands, Chinabank, Robinson's Bank and Banco de Oro, which are all located within the vicinity of Bulacan State University which also includes Graceland Mall in the City of Malolos. The study also aims to determine which factors have the significant effect on the interaction between humans and ATMs, and to evaluate the usability of the said ATMs and its effectiveness to users. The researchers conducted the study from the month of August up to the month of September of the current year. Survey, Queueing process and time experiment was used to support the study. The aspects look into are the visibility of the systems status and feedback on the user, meaningful labels and descriptive
\end{abstract}

Journal of Industrial Engineering and Management Science, Vol. 1, 49-102.

doi: 10.13052/jiems2446-1822.2017.004

(c) 2017 River Publishers. All rights reserved. 
links, match between the system and the real world, user control and freedom, consistency, error prevention, learnability and memorability, flexibility and efficiency of use, aesthetics and satisfaction. Only those who have completely accomplished all the questions were considered in the study. The goal of the study is to establish an ergonomically designed ATM interface that will suffice users' needs as well as is suitable for its intended task.

Keywords: ATMs, queueing process, survey, human-computer interaction, interface.

\section{Introduction}

Human-computer interaction researches started to grow in 1960s. It was supported by different fields such as anthropology, cognitive psychology, cognitive science, experimental psychology, ergonomics and human factors. Even though there are almost, millions of Automated Teller Machines (ATMs) available in the world, users of the machine still have usability problems including inappropriate user - ATM interaction, display problems and others.

This study aims to analyze the human-computer interaction and usability evaluation of Automated Teller Machines (ATM) in which banks use different interface design in their own ATMs. ATM was introduced to Philippines in the 1980s Automated Teller Machine is a device used by bank customers to make a basic transaction like withdrawing money, checking balance account without the help of any bank teller. The country's ATM network grew by 175 percent between 2001 and 2011 - from less than 4,000 ATMs in 2001 to over 10,000 ATMs in 2011, according to data from the Bangko Sentral ng Pilipinas. (Philippine Daily Inquirer, 2013). The study also aims to compare the data gathered from different ATMs from different banks like Landbank of the Philippines (LBP), Bank of the Philippine Island (BPI), Chinabank, Robinson's bank, and Banko de Oro (BDO) and evaluate the problems encountered by users such as captured cards. Also, the customer satisfaction in using the mentioned ATMs are measured by the researchers with the use of different factors considered such as follows: visibility of the systems status and feedback on the user, meaningful labels and descriptive links, match between the system and the real world, user control and freedom, consistency, error prevention, learnability and memorability, flexibility and efficiency of use, and aesthetics. A questionnaire is used to determine the problems encountered by users, preferred ATM to use, and the rate of satisfaction the users can 
give after using the machine. After conducting the study, the researchers will recommend an ergonomically designed interface which can finally and fully satisfy the customer's needs.

\subsection{Study Objectives}

The main objective of the study is to determine which among the Automated Teller Machines (ATM) on Landbank of the Philippines (LBP), Bank of the Philippine Island (BPI), Chinabank, Robinson's bank, and Banko de Oro (BDO) has the most ergonomically designed interface and which factors affect the usability of the machine.

The study sought to achieve the following objectives:

- To conduct a comparative study between five different ATMs (LBP, BPI, Chinabank, Robinsons bank and BDO).

- To determine which factors have the significant effect on the interaction between humans and ATMs.

- To evaluate the usability of the five ATMs and its effectiveness to users.

- To minimize captured cards among ATM users with little knowledge and experience.

- To establish an ergonomically designed ATM interface that will suffice users' needs as well as is suitable for its intended task.

\subsection{Rationale of the Study}

This study is conducted to assess the human-computer interaction and usability evaluation of different Automated Teller Machines (ATM). This study is conducted to know the design interface of automated teller machine of different banks. This study contains information through observing different ATM's bank. Using these data, the researchers shall develop or recommend an ergonomically designed interface. The recommendation of ergonomically designed interface is a tool in improving the level of effectiveness of the interface that will be beneficial for the users and different banks. Furthermore, the study with such interests of the researchers must successfully accomplish the study to complete the ergonomically designed interface.

\subsection{Significance of the Study}

To the Student Researchers, the study will be beneficial for the assessment of their knowledge and expansion of skills in the application of Human Factors Engineering by improving and analyzing the present design and minimizing problems encountered of users in using ATM. 
To the ATM users, the study will help them understand the basic knowledge in using automated teller machines. This can also help the users to have a machine easier to use through suggestions gathered and by providing recommendations to achieve the desired outcome that can satisfy their needs.

To the Company/Bank, the study will help them know the problems encountered by users while using their ATMs and to improve by recommending a more user-friendly and ergonomically designed interface of their ATMs.

To the Future Researchers, this study will be beneficial to other researchers because this will provide the findings and analysis. This study can be a basis on recommending ATM design with ergonomically designed interface. The weaknesses of the study will also benefit other researchers for their future studies as areas for improvement.

\subsection{Problem Statement}

The usage of Automated Teller Machines (ATM) are widely trendy nowadays. It is easier for people to withdraw money whenever they need it. Almost all vicinities have different kind of banks that offer ATMs. Most of the bank customers are familiar on the said device, however not all of them can use the machine effectively. Some customers experienced captured cards. As shown on Figure 1, almost 12\% of the surveyed ATM users happen to get their cards stuck on the machine. This is not good thing, especially for those who really need cash. It takes about three days for a customer to retrieve his card whenever it was captured. This may result to customer dissatisfaction.

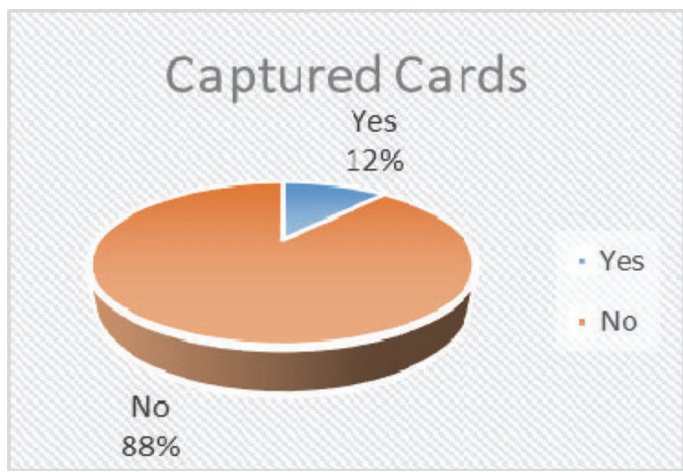

Figure 1 Percentage of customers who encountered card capturing. 
Table 1 Captured cards

\begin{tabular}{lcc}
\hline Banks & Transact & Captured Card \\
\hline BPI & 82 & 11 \\
BDO & 65 & 4 \\
LANDBANK & 67 & 13 \\
CHINABANK & 17 & 0 \\
ROBINSON'S BANK & 10 & 0 \\
\hline
\end{tabular}

The Table 1, shows the number of ATM users that encountered their card captured by the machine and in which bank they transacted. These data are based on the results of the survey that the researchers have conducted. Landbank has the highest number of ATM users that encountered card captured followed by the BPI and then BDO users. Chinabank and Robinson's Bank users, based on the results, have no records of card captured.

The objective of this study is to conduct a comparative study between the five ATMs mentioned earlier. The researchers measured the effectiveness of the ATM of different banks (LBP, BPI, Chinabank, Robinsons bank and BDO) based on customer satisfaction. Customer satisfaction is a term used to measure how products or services provided by a firm or organization meet or surpass the expectation of the customers. It is an important factor for capturing the market and also for retaining the existing customers. The factors that may affect the customer satisfaction in the usage of ATMs are as follows: visibility of the systems status and feedback on the user, meaningful labels and descriptive links, match between the system and the real world, user control and freedom, consistency, error prevention, learnability and memorability, flexibility and efficiency of use, and aesthetics.

\subsection{Scope and Limitation}

The study focuses on the interaction between Automated Teller Machines (ATM) and its users. It also focuses on the machine's interface and conformity for users. ATMs of Landbank of the Philippines (LBP) on Bulacan State University and Bank of the Philippine Islands (BPI), Chinabank, Robinsons bank, and Banko de Oro (BDO) on Graceland Mall, Malolos, Bulacan were the machines considered on the study. Data are gathered through observations and surveys from the users of the mentioned banks above.

The study was conducted from the month of August until September. One hundred ATM users that transact to any of at least two out of five mentioned banks above were surveyed. The aspects look into are the visibility of the 
systems status and feedback on the user, meaningful labels and descriptive links, match between the system and the real world, user control and freedom, consistency, error prevention, learnability and memorability, flexibility and efficiency of use, aesthetics and satisfaction. Only those who have completely accomplished all the questions were considered in the study.

Also, the researchers focuses on the ergonomic aspect of the ATMs. The recommendation will revolve only on the design interface of the ATMs.

\section{Review of Related Literature}

According to Trading Economics, ATM is defined as "computerized telecommunications devices that provide clients of a financial institution with access to financial transactions in a public place". ATM was the first well-known machine that provides electronic access to customers that brought a less hassle, and easier transaction of the customer and the bank. But through the years, there are still glitches encountered by users in using the machine which led researchers to conduct studies to eliminate or minimize the encountered problems.

In the present paper, we will be going to evaluate the usability of the ATMs on Bulacan State University and Graceland Mall, Malolos, Bulacan and its effectiveness to users. The researchers of the present paper will also conduct a comparative study between the five ATMs, and establish an ergonomically designed ATM interface that will satisfy the needs of users. The following related literatures can support the present study.

The study of Sultan Singh, Ms.Komal, (Ph.D.) "Impact of ATM on Customer's Satisfaction" can be a support in this study, wherein Singh and Komal examined the impact of ATM on customer's satisfaction by evaluating the problems faced by the customers while using the machine. As stated by PeeyushAgnihotri in his paper "IT way of getting cash", "providing ATM facility is just a value-added service to make the customers happy", with most of the banks providing 24/7 service, and allowing to transact to other ATMs even when the customer is not listed in that bank, these services can somehow give comfort and satisfaction to customers.

"A Survey on Human Computer Interaction Technology for ATM" by Mengxing Zhang, Feng Wang, Hui Deng, and Jibin Yin can also be a support in this study where they evaluate the user's experience while using the ATM then evaluated and discussed the details and found the defects and possible improvements for the ATM design, wherein they found out that there are still many troubles that customers encountered while using the ATM because of poor interface design. 
The study of Dr. R. Seetha Lakshmi and Dr. P. Kavitha entitled "Customer Satisfaction in ATM Services: A study with the Reference to Indian Bank at Tiruchirappalli Corporation" can also be a support in this paper wherein after Dr. Lakshmi and Dr. Kavitha conducted their study, they found out that there is no relationship between the demographic factors and customer satisfaction which can be related and can be of used in one of the objectives of this study which is to determine which factors have significant effect on the interactions between the user and the ATMs. The authors of this study also recommended that banks should proactively monitor customers' preferences with regard to the transaction fee; delivering of ATM card promptly. These recommendations can also be related to one of the objectives of our study which is to minimize the captured cards among ATM users.

According to the study entitled "Customer Satisfaction of Automated Teller Machine (ATM) Base on Service Quality" by Bashir Idris, the author mentioned in this study that Automated Teller Machines is one of the services introduced by banks with the objective of providing customers with quick access to their finance, or offers their customers quick and reliable services with just a click on the machine. The author also used questionnaires that includes perceived ease of use, perceived accessibility and perceived security in order to measure customer satisfaction in relation to ATM service quality. The factors the author used in his study can be helpful on the present paper to be able to identify the satisfaction of customers in using ATMs in the five banks mentioned earlier in the paper. These factors can also be used in order to evaluate the effectiveness and usability of ATMs to its users.

While in the study of Charles Mwatsika entitled "Factors Influencing Customer Satisfaction with ATM Banking", the author mentioned in his paper that identifying the key features of ATM banking that has something to do with customers' satisfaction must be needed to know by the bank manager's in order to achieve competitive advantage in the industry. In the latter part of the study, the author found out that reliability and responsiveness are the key service quality dimensions of ATM banking. He also mentioned the 12 key attributes that can be influential in customers' satisfaction and these are: ATM fees charged, ATMS not out of order, cleanliness of ATMs and ATM stations, accuracy of ATM transactions, ease of access to ATMs, readable slips, convenient location, employee accessibility to solve ATM problems, privacy at ATM stations, employee speed in solving ATM issues, ease of application process for ATM cars and cash availability in ATMs.

In another study entitled "Customers' Satisfaction and ATM Services: The Case of Bangladesh", Tajul Islam found out after conducting the study that 
security, safety and privacy of ATM are the most important and represents maximum satisfaction of ATM users. Throughout the study, the author also then found out that the customers are satisfied with almost all the services being offered by ATMs which includes the speed of delivery of ATM cards, maximum limit of cash withdrawals, quality of notes, PIN of ATM card, cash withdrawal and accuracy/swiftness, sufficient cash in ATM. These factors were used by the author in order to identify of the users are satisfied or not, and used descriptive analysis and statistical analytical tools to interpret the data gathered.

\section{Methodology}

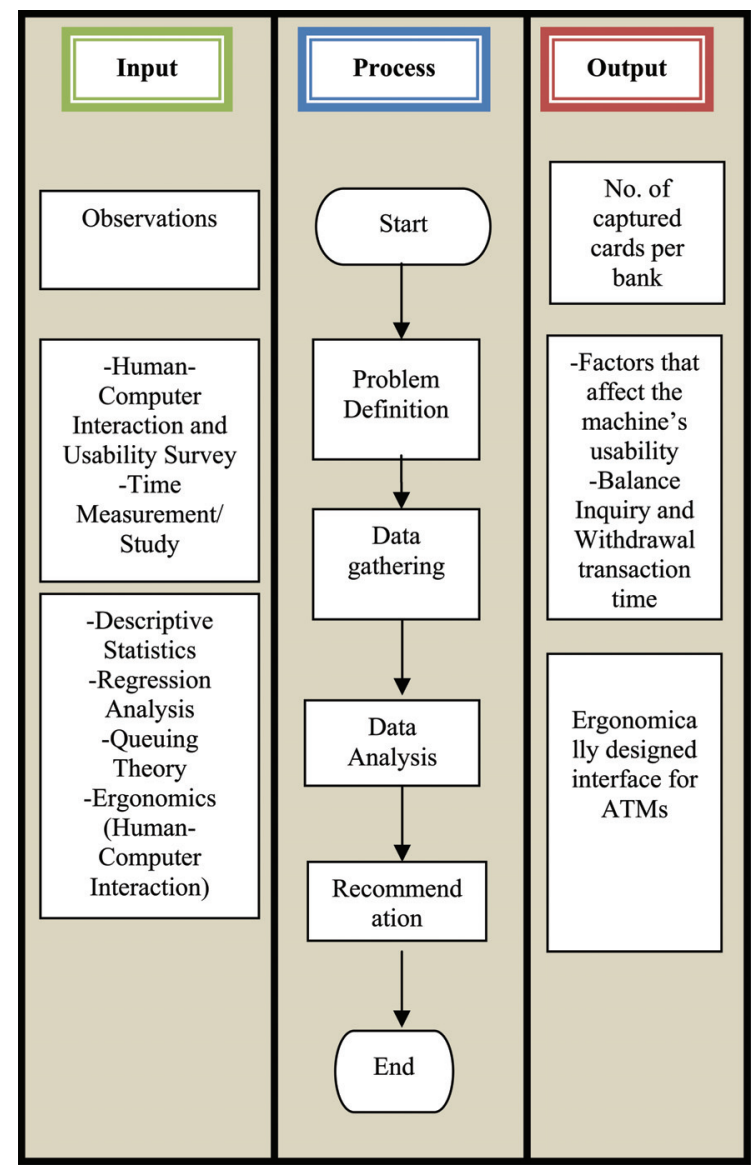

Figure 2 Methodology of the Study. 


\subsection{Sampling Procedure}

The survey questionnaire was provided to the ATM users that transact to any of at least two out of five given banks (LBP, BPI, Chinabank, Robinsons bank and BDO). Using random sampling, one hundred questionnaires are distributed to ATM user of the five banks mentioned. Only those respondents who have accomplished the questionnaires completely were considered in the study.

\subsection{Research Instrument}

The primary instrument used in this study is the questionnaire. Questionnaire method is widely used because it is cost effective, saves time and data can be collected at a short period of time (John Arul Phillips 2010).

After reading and studying samples of questionnaires from related studies mentioned on the previous chapter, the researchers prepared their own questionnaire that was finalized by their instructor.

In this research, to develop a reliable and valid measurement, the questionnaire is divided into two parts namely familiarization and usability evaluation.

\section{Part A: Familiarization}

In this section, personal variable questions consists of the demographic profile of the respondents will be given. Questions about gender, age, and language preference will be answered. This will show their agreement on answering the surveys. Also, it includes questions regarding their ATM bank preference, list of activities they do on ATM, and if they ever encountered captured cards.

\section{Part B: Usability Evaluation}

In this section, the customer's satisfaction in using the ATM will be tested. Questions based on factors that affect the customer's satisfaction are requested to be answered confidentially. The respondents' are allowed to take their time on answering the surveys. Part B consists of thirty-four (34) questions.

\begin{tabular}{|l|l|}
\hline Visibility of the Systems Status and Feedback on the User & 1 question \\
\hline Meaningful Labels and Descriptive Links & 4 questions \\
\hline Match between the System and the Real World & 4 questions \\
\hline User Control and Freedom & 3 questions \\
\hline Consistency & 4 questions \\
\hline Error Prevention & 3 questions \\
\hline Learnability and Memorability & 4 questions \\
\hline Flexibility and Efficiency of use & 3 questions \\
\hline Aesthetics & 6 questions \\
\hline Customer's Satisfaction & 4 questions \\
\hline
\end{tabular}




\subsection{Data Analysis and Presentation}

Since the collected data were quantitative, quantitative methods were adopted to analyze the data. Those data obtained through close ended questionnaire were presented in tables and analyzed by frequency counts and percentages. Percentage was also used to examine the personal characteristics of respondents and to check the disparity in responses among different group of respondents on the usability evaluation affecting customer satisfaction. Multiple regression analysis, will be applied as there are more than one independent variable affecting dependent variables. Minitab was used to examine the significant differences that exist among the means of the respondents of the five banks (LBP, BPI, Chinabank, Robinsons bank and BDO)) regarding factors that affect customer satisfaction and to test the significant differences among means of responses in groups at alpha 0.05 level. Mean score of each group and total mean of the groups are also used for the analysis. In addition, queuing theories are used to further measure the effectivity of the ATMs. A Poisson distribution is a discrete probability distribution used to identify the average rate of people transacting on each of the five studied banks per hour. Furthermore, a comparative study between the ATMs was made according to the factors that affect the usage of human on the machine. Data are obtained through interview and documents were organized and presented through narrative descriptions.

\subsection{Tools Used for Data Analysis}

The researchers used Microsoft Excel to present the tallied surveys. Charts were also used to present the data collected from surveys which is used for the comparison study between the ATMs. To measure the service capacity of an ATM, a queuing model was used. The researchers also used Minitab 16 for data analysis. This statistical software provides necessary calculations and information about the variables used in the study.

\subsection{Conceptual Model}

Human and Computer Interaction depends on the users perception of how they will use the machine, the problems that they encounter in using the machine, and the application of human physical, cognitive, social and affective knowledge to the design of the system.

The effectiveness of the ATMS depends on how it satisfies the customers or users of the machine, whether there are only minimal cases of captured 
cards, and if the design interface of the ATM serves its basic functions such as withdrawal, balance inquiry and deposit. The effectiveness of the ATMs of five banks (LBP, BPI, Chinabank, Robinsons bank and BDO) are measured using a survey questionnaire distributed to the users of the said banks. The effectiveness of Human-Computer interaction in ATMs may be related to the customer satisfaction.

The conceptual model (Figure 3) has the dependent variable, HumanComputer Interaction as related to the customer satisfaction, and the independent variables namely the factors affecting the usability of ATMs (visibility of the systems status and feedback on the user, meaningful labels and descriptive links, match between the system and the real world, user control and freedom, consistency, error prevention, learnability and memorability, flexibility and efficiency of use, and aesthetics).

\subsection{Hypothesis}

According to this study some of the factors (visibility of the systems status and feedback on the user, meaningful labels and descriptive links, match between the system and the real world, user control and freedom, consistency, error prevention, learnability and memorability, flexibility and efficiency of use, and aesthetics) affect the customer satisfaction in using an ATM.

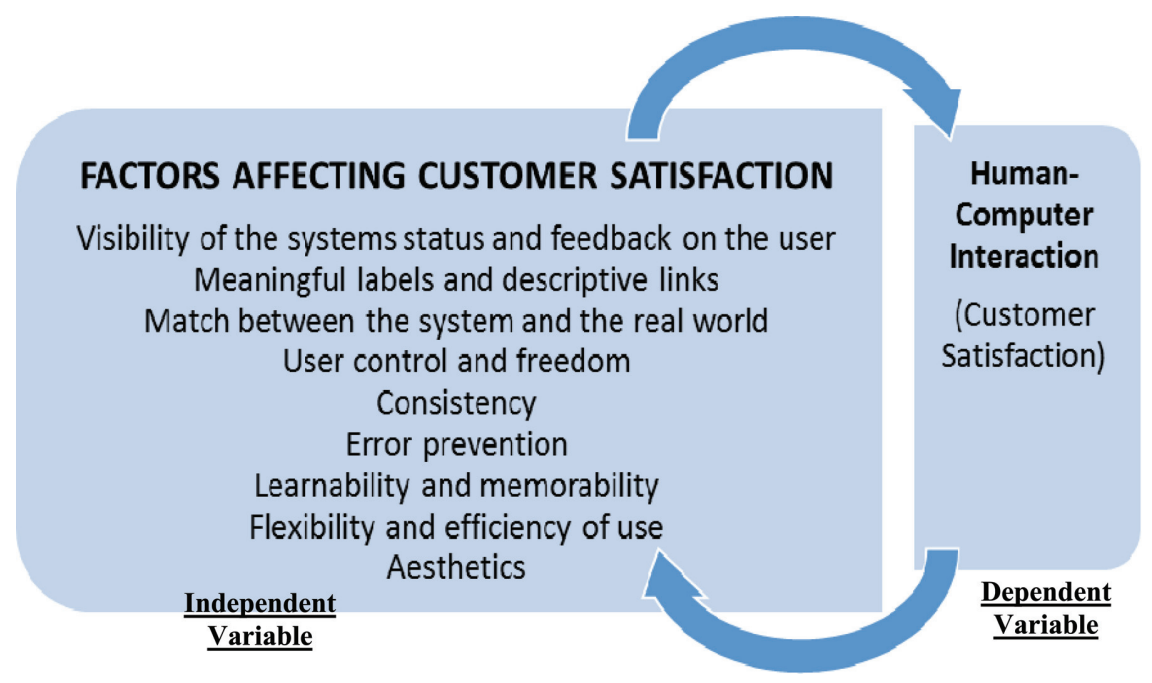

Figure 3 Conceptual framework. 
Visibility of the systems status and feedback on the user. The visibility of the system reflects to the interface's degree of clearness. If the system is not clear on the eyes of the customer, it will be unsatisfying for them to use the machine.

Meaningful labels and descriptive links. Labels and descriptive links are used to support recognition to users. This factor shows if the options presented on the system corresponds its intended function.

Match between the system and the real world. System's interface must correspond with human's basic understanding. This factor shows whether users were satisfied with the system's conformity with the real world.

User control and freedom. The user must be able to customize the system for his/her preference. This factor shows that users can change the system's basic interface and configuration based on how they want it to be.

Consistency. The system must have consistency and adherence to standards. The prompts and messages should appear to the same place on the screen as well as the command buttons.

Error prevention. The system should be designed to prevent serious errors. This is the most significant factor that affects the capturing of cards among users. For a system to be satisfying for the customers, error messages should be appropriate and understandable. Also, it should have a proper procedure for error prevention and recovery.

Learnability and Memorability. The system should be designed in a way that its adaptable to customers. This factor simply concentrates on the easy learning of the system for the users. For a system to be effective, the sequences of actions and items should be easy to remember and the instructions and informations given by the system should be easier to learn.

Flexibility. The system should cater both novice and expert users. This factor measures the system's user friendliness and efficiency. It should be compatible with the customer's stimuli response. It should be easy for the users to understand the ystem, especially for the first time users. Shortcuts for frequent users can also be included for better satisfaction.

Aesthetics. The system's interface should be designed efficiently. Layout must capture user's attention. This factor sums up the overall visual design of the system. The colors, fonts, graphics, backgrounds and icons should be harmonious and compatible with each other. Also, the screen should not appear to be cluttered. 
Customer Satisfaction. User satisfactory shows the overall user's experience on operating the system. It is a marketing term that measures how products or services supplied by a company meet or surpass a customer's expectation. It is important because it provides marketers and business owners with a metric that they can use to manage and improve their business. The satisfaction of the customers is used as a measurable factor for the system's effectiveness. The users utilizing the ATM have a better satisfaction if the system is efficient and effective in terms of the factor listed above.

Null Hypothesis: All factors (visibility of the systems status and feedback on the user, meaningful labels and descriptive links, match between the system and the real world, user control and freedom, consistency, error prevention, learnability and memorability, flexibility and efficiency of use, and aesthetics) have no significant effect on the effectiveness of the ATM which is associated to the customer's satisfaction.

Alternative Hypothesis: At least one of the factors (visibility of the systems status and feedback on the user, meaningful labels and descriptive links, match between the system and the real world, user control and freedom, consistency, error prevention, learnability and memorability, flexibility and efficiency of use, and aesthetics) has a significant effect on the effectiveness of the ATM which is associated to the customer's satisfaction.

\section{Results and Discussions}

This paper presents the result of the data gathering from the ATM users from five banks - Landbank of the Philippines (LBP), Bank of the Philippine Island (BPI), Chinabank, Robinson's bank, and Banko de Oro (BDO) in accordance to the factors affecting customer satisfaction. The survey was distributed on one hundred fifty (150) respondents that transacts on the ATM on Graceland Mall, Malolos, Bulacan.

A random sampling is made on the one hundred fifty (150) respondents. Each bank have atleast twenty five (25) respondents. Respondents who transacts to atleast two of the mentioned banks are considered to the study. Only one hundres (100) respondents completed the survey and were considered in the study. The researcher presents the summary of demographic profile by graph and used software product analysis of Minitab to interpret the result based on the survey collected. 


\subsection{Demographic Profile of Respondents}

This section shows the personal variable questions consists of the demographic profile of the respondents. The results on the questions about age, gender, language preference, captured cards, name of banks usually transacting, and the list of activities done on the ATM.

Figure 4 presents the age of the respondents. General respondents of twenty-eight respondents belong to 19 years of age. The 20 year old have comes next which comprises 20 respondents. Followed by the 21 year olds, 18 and 24 year olds, 17, 25, and 30 year olds, and then the 48 year olds. The remaining respondents falls to the unmentioned age.

Figure 5 shows that out of one hundred respondents, 59\% are female and $41 \%$ are male which means a majority of the total sample populations are females.

\section{Respondent's Age}

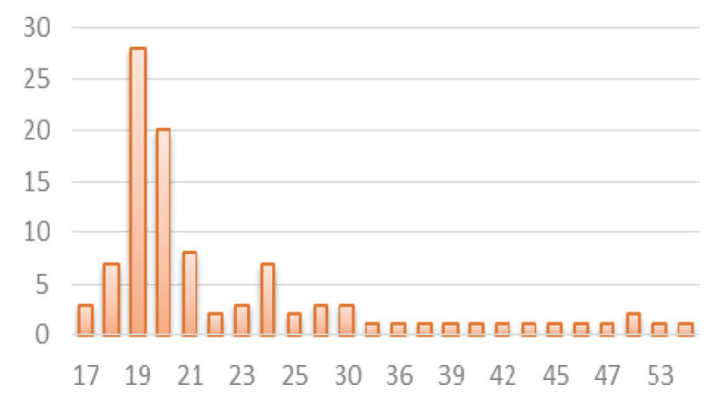

Figure 4 Respondent's age.

\section{Respondent's Gender}

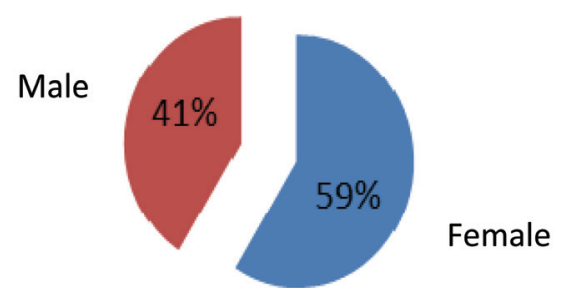

Figure 5 Gender. 
Figure 6 shows the language preference of the respondents. Out of onehundred respondents, 59\% preferred Taglish while $41 \%$ preferred English. It shows 11 that there is higher percentage of users who preferred ATMs with Taglish directions and options than English.

Figure 7 presents the frequency and distribution of the respondent's bank. The data is not enclosed to the specific bank the user is a client of. It can also means all the ATM used by that customer. The pie chart shows that the Bank of the Philippine Islands (BPI), is the machine mostly used by our respondents, followed by Landbank, Banco de Oro (BDO), Chinabank, and Robinson's Bank respectively.

\section{Preferred Language}

-TAGLISH ENGLISH

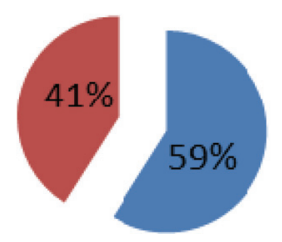

Figure 6 Preferred language.

\section{Percentage of banks used}

$\square$ BPI $\square$ BDO $\square$ LANDBANK $\square$ CHINABANK $\square$ ROBINSON'S BANK

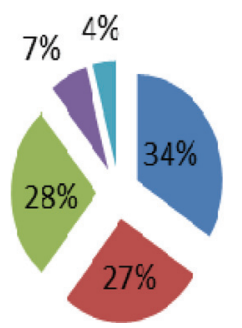

Figure 7 Banks (Percentage). 
Captured card is one of the problems encountered by ATM users. On the survey we have conducted, 28 out of 100 said that they have experienced their card being captured while using ATM, and 72 out of 100 said that they have not experience their cards being captured with any of the 5 banks included in the study. Figure 8 shows the percentage of captured cards. $28 \%$ answered yes on experiencing captured cards and $72 \%$ answered no.

Figure 9 shows the percentage of where respondents have experienced their cards being captured. Landbank has the highest percentage with 47\%, followed by Bank of the Philippine Islands (BPI) and Banco de Oro (BDO) having 39\% and 14\% respectively. The Chinabank and Robinson's bank have no record of captured cards based on the result of the researchers' survey.

\section{Percentage of captured cards}

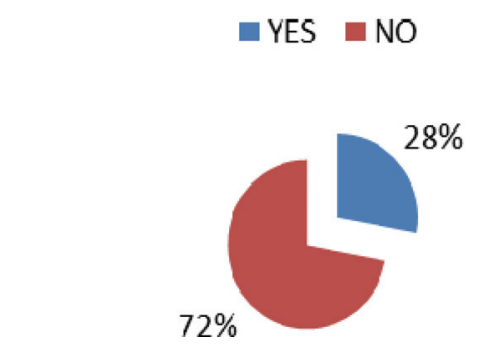

Figure 8 Captured cards.

\section{ATMs where customers experienced captured cards}

$\square \mathrm{BPI}=\mathrm{BDO} \square$ LANDBANK

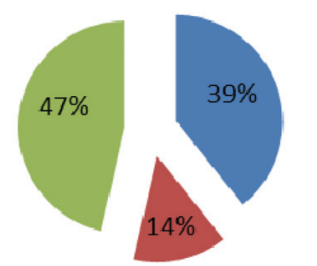

Figure 9 Banks (ATM) where captured cards occur. 


\section{Activities usually done in ATMs}

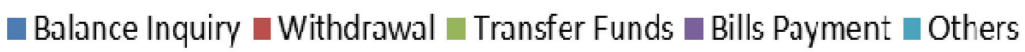

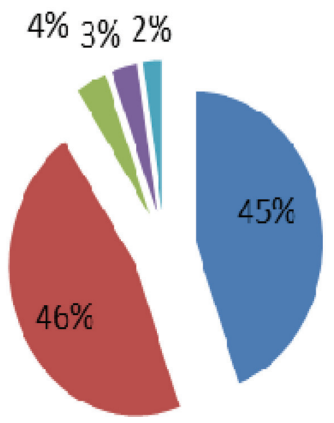

Figure 10 List of activities done in ATMs.

Researchers have also gathered information for the activities usually done by ATM users. There are four basic transactions: balance inquiry, withdrawal, transfer funds, and bills payment. Figure 10 shows that withdrawal has the largest percentage which is $46 \%$. The balance inquiry also have a large percentage which is $45 \%$. Followed by transfer funds (4\%), bills payment $(3 \%)$ and others $(2 \%)$. Others include changing of pin, check book recorder.

\subsection{Factors Affecting the Effectiveness of Automated Teller Machine (ATMs) Based on Customer Satisfaction}

The effectiveness of Automated Teller Machines (ATMs) are measured in terms of customer satisfaction while using the machines of the five given banks - Landbank of the Philippines (LBP), Bank of the Philippine Island (BPI), Chinabank, Robinson's bank, and Banko de Oro (BDO). Questions based on the factors that affect customer satisfaction are made by the researchers and the respondents are requested to answer the questions confidentially. The factors considered are as follows: visibility of the systems status and feedback on the user, meaningful labels and descriptive links, match between the system and the real world, user control and freedom, consistency, error prevention, learnability and memorability, flexibility and efficiency of use, and aesthetic. 
The Likert Scale was used to measure and evaluate the respondents' answers. The Likert scale is a rating scale, which measures the strength of agreement with a statement (John Arul Phillips, 2010). The choices of responses for each of the statement designed was constructed using the 5point Likert scale. The type of rating scale used is "Agreement" and the ratings scales are as follow:

\begin{tabular}{|l|l|}
\hline Code & Interpretation \\
\hline 5 & Strongly Agree \\
\hline 4 & Agree \\
\hline 3 & Not Sure \\
\hline 2 & Disagree \\
\hline 1 & Strongly Disagree \\
\hline
\end{tabular}

The customer satisfaction of the ATM users are also measured using the Likert scale. The researchers included that information to the survey questionnaires. There are two items comprising the customer satisfaction: the interface of the system was pleasant and the user is satisfied with the use of this system.

Figure 11 shows the results of satisfaction from the five different ATMs. The interface of the system was pleasant has the highest result for this factor; BPI has the highest number of respondents that agreed, followed by Landbank, BDO, Chinabank, and Robinson's bamk respectively.

\section{Satisfaction}

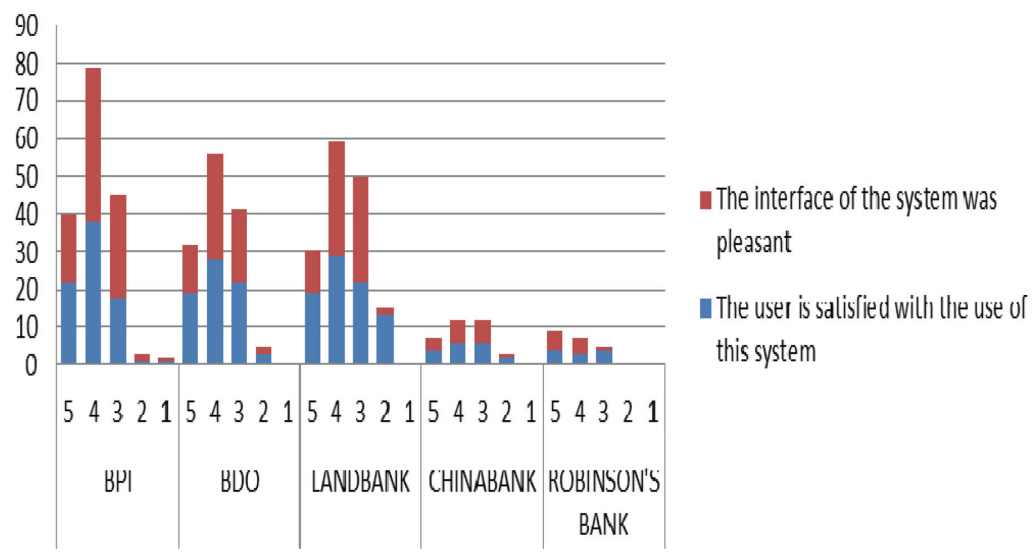

Figure 11 Satisfaction. 


\subsection{Descriptive Statistics}

There are nine factors (visibility of the systems status and feedback on the user, meaningful labels and descriptive links, match between the system and the real world, user control and freedom, consistency, error prevention, learnability and memorability, flexibility and efficiency of use, and aesthetic) considered in this study that may affect the customer satisfaction in using the ATMs. The figures below show the results of the survey. The section also shows the overall mean score values of the nine factors.

The visibility of the system reflects to the interface's degree of clearness. Figure 12 shows that most of BPI, BDO and Landbank customers who uses their ATMs agreed that the related information or options of the machines they have used are logically grouped and labelled. Users of BPI, BDO, Landbank, and Robinson's bank were satisfied with the systems visibility. Users of China bank were neither satisfied nor unsatisfied. Robinson's bank has the highest rate for this factor while Chinabank has the lowest. It shows that the Chinabank's interface was not labelled effectively. It is hard for the users to identify the function of the activities provided by the system.

Questions rated on this factor includes whether the related information or oprtions are logically grouped and labelled.

\section{Visibility of the system status and Feedback on the user}

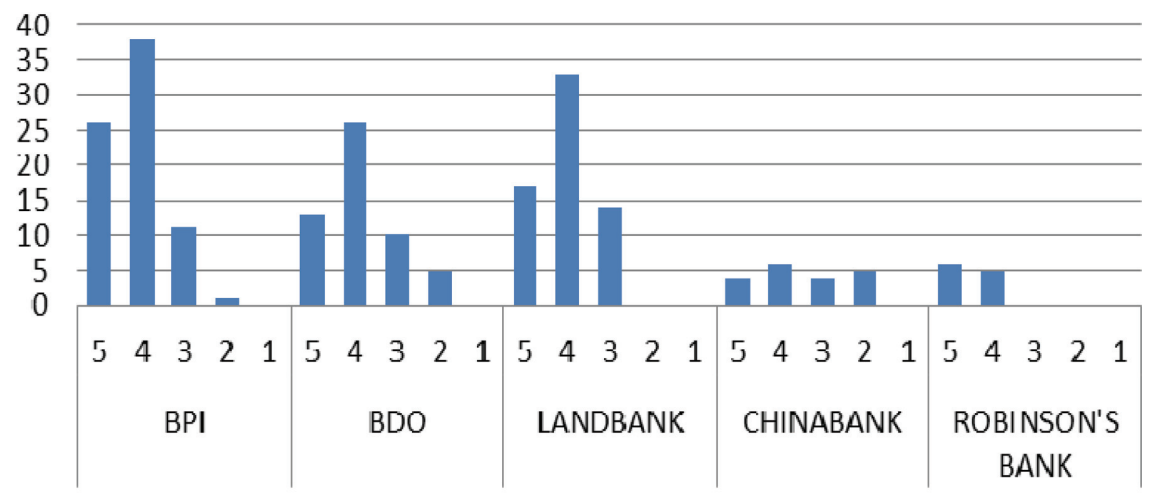

Related information or options are logically grouped and labeled

Figure 12 Visibility of the system. 
Labels and descriptive links are used to support recognition to users. This factor shows if the options presented on the system corresponds its intended function. Selection of an option clearly identifies its intended functions has the highest result for this factor, BPI has the highest number of respondents that agreed at the said usability problem. Users were neutral on their stand with this factor. BPI, BDO, Landbank, Chinabank, and Robinson's bank users were neither satisfied nor unsatisfied with the systems' label and links. Robinson's bank has the lowest rating. The Robinson's bank doesn't show the command selected by the user and the action made by the network which makes it confusing for the users. In addition, feedbacks were not given by the system.

Questions rated on this factor includes the following: selection of an option clearly identifies its intended functions, selected items are highlighted/differentiated from the rest of unselected items, feedback is provided when a certain action is done in the system, and the users can see where they are in the overall system at all times.

\section{Meaningful labels and descriptive links are used to support recognition}

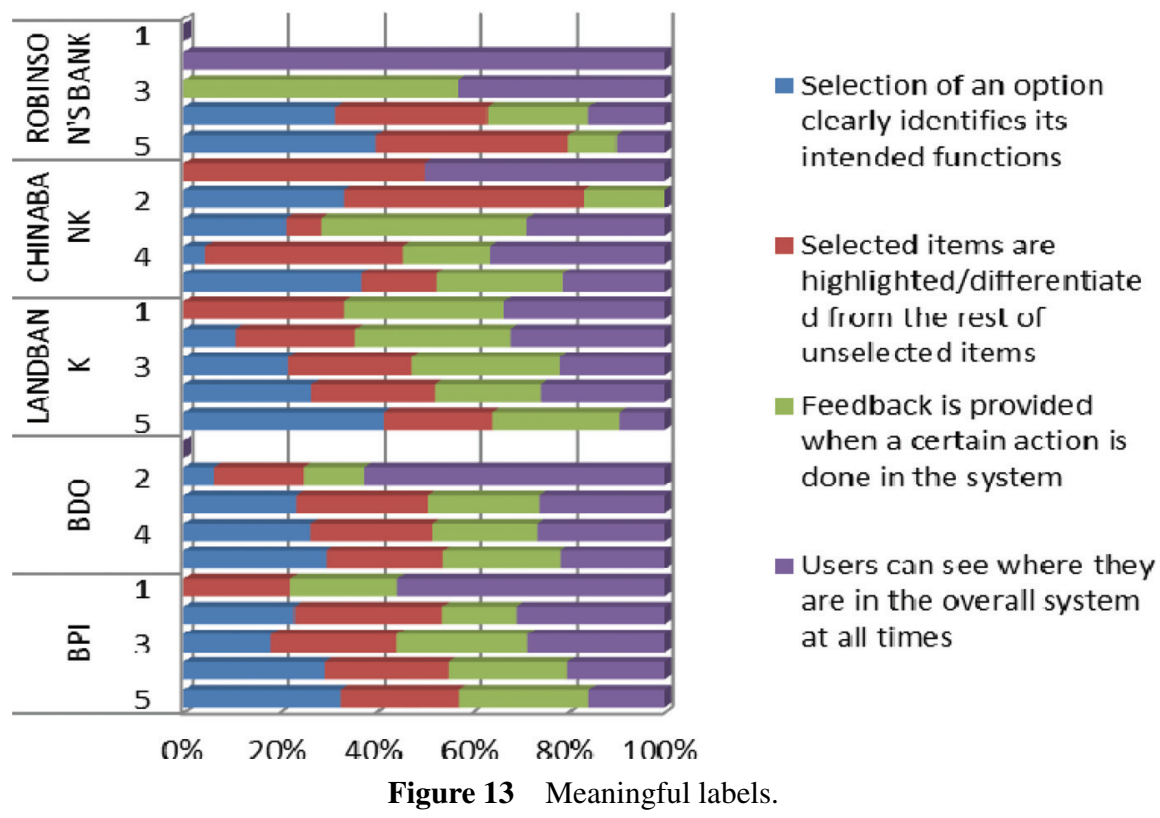


On Figure 14 are the results of match between the system and the real world from the five different ATMs. Language used is understandable and similar to the language of the users (academic) has the highest result for this factor, BPI has the highest number of respondents that highly agreed at the said usability problem. System's interface must correspond with human's basic understanding. Users of BPI and BDO were satisfied with the system's conformity with the real world. Landbank, Chinabank, and Robinson's bank users were neutral on their stand for this factor. Robinson's bank has the lowest rating. Languages and symbols used in the Robinson's bank's interface are not similar with what is used on the real world. Furthermore, the information presented was not arranged logically with regards to human's natural knowledge.

Questions rated on this factors includes the following: language used is understandable and similar to the language of the users (academic), symbols, icons, and names used correspond to real-world objects and concepts, symbols, icons, and names used correspond to the tasks, and the information is presented in a natural and logical order.

\section{Match between the system and the real world}

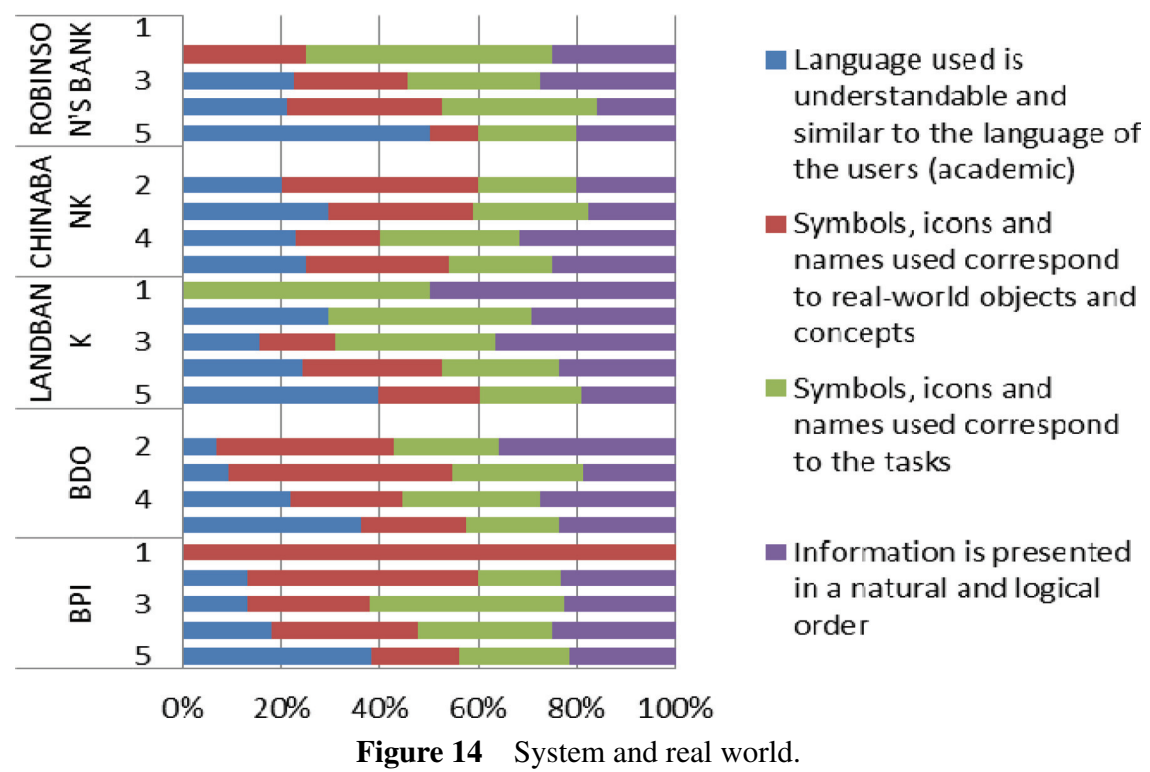


70 M. B. Calayag et al.

\section{User control and freedom}

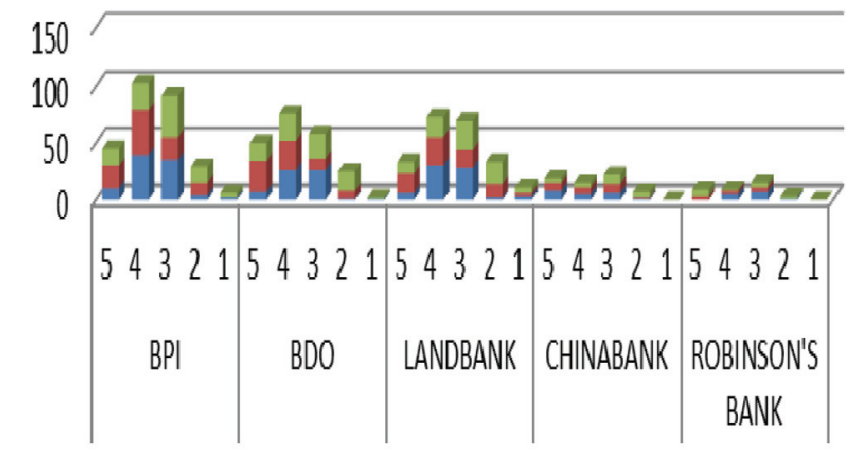

- Undo and redo actions are possible in the system

IIt allows users to exit any time when errors are made

IIt allows modification/customization of basic system configuration to suit user's needs

Figure 15 User control.

The bar chart on Figure 15 shows the results of user control and freedom from the five different ATMs. It allows users to exit any time when errors are made has the highest result for this factor, BPI has the highest number of respondents that agreed at the said usability problem. This factor shows that users can change the system's basic interface and configuration based on how they want it to be. BDO has the highest rate for this factor and Landbank has the lowest. It shows that the Landbank's system interface doesn't allow the user to exit and undo or redo the action that was made. Even though, users show a neutral stand for this factor. BDO, BPI, Landbank, Chinabank, and Robinson's bank users were neither satisfied nor unsatisfied with the systems degree of freedom.

Questions rated on this factor include the following: undo and redo actions are possible in the system, it allows users to exit anytime when errors are made, and it allows modification/customization of basic system configuration to suit user's needs.

The stacked bar chart on Figure 16 shows the results of consistency and adherence to standards from the five different ATMs. The same concepts, 


\section{Consistency and adherence to standards}

- Prompts and error messages appear in the same place on the screen

- There is adequate back button to return to a previous page

- The same concepts, words, symbols, situations or actions refer to the same thing

Each page is displayed in the same design principle/s

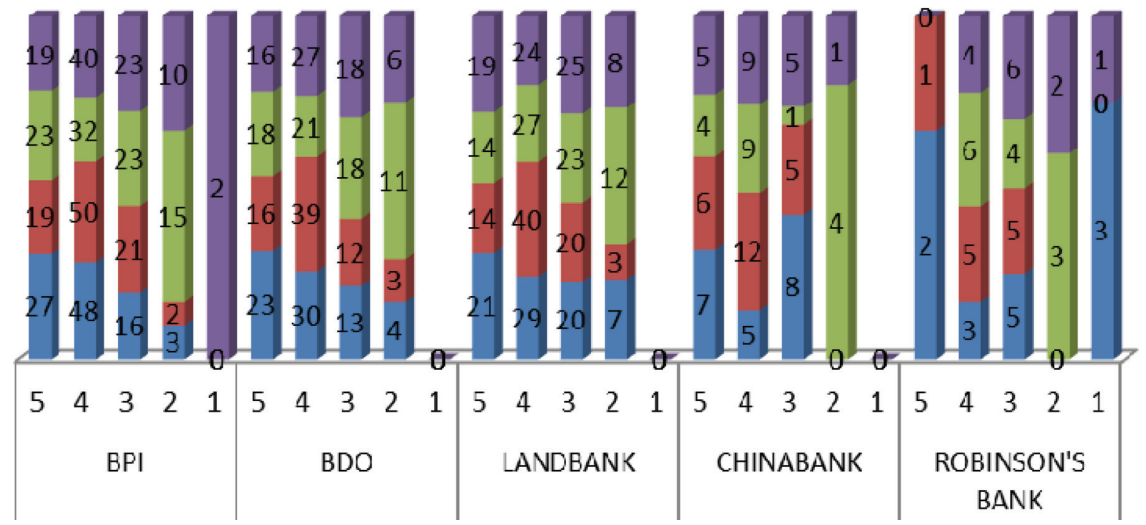

Figure 16 Consistency.

words, symbols, situations or actions refer to the same thing has the highest result for this factor, BPI has the highest number of respondents that agreed at the said usability problem. The system must have consistency and adherence to standards. Users of BDO, BPI, Landbank, Chinabank, and Robinson's bank were neither satisfied nor unsatisfied with regards to this factor. Robinson's bank has the lowest rating. The design, concepts, and symbols on the Robinson's bank's interface are not consistent which makes it hard for the users to understand and learn the system. Also, the prompts and messages provided by the system are not appearing on the same place on the screen.

Questions rated on this factor includes the following: prompts and error messages appear in the same place on the screen, there is adequate back button to return to a previous, the same concepts, words, symbols, situations or actions refer to the same thing, and each page is displayed in the same design principle/s.

The stacked bar chart on Figure 17 shows the results of error prevention from the five different ATMs. Appropriate and understandable error messages are prompted and expressed in plain language when errors occur refer to the 


\section{Error prevention}

[rror messages identify the specific problem and give instructions for recovery

- Appropriate and understandable error messages are prompted and expressed in plain language when errors occur

- The system is designed to prevent serious errors

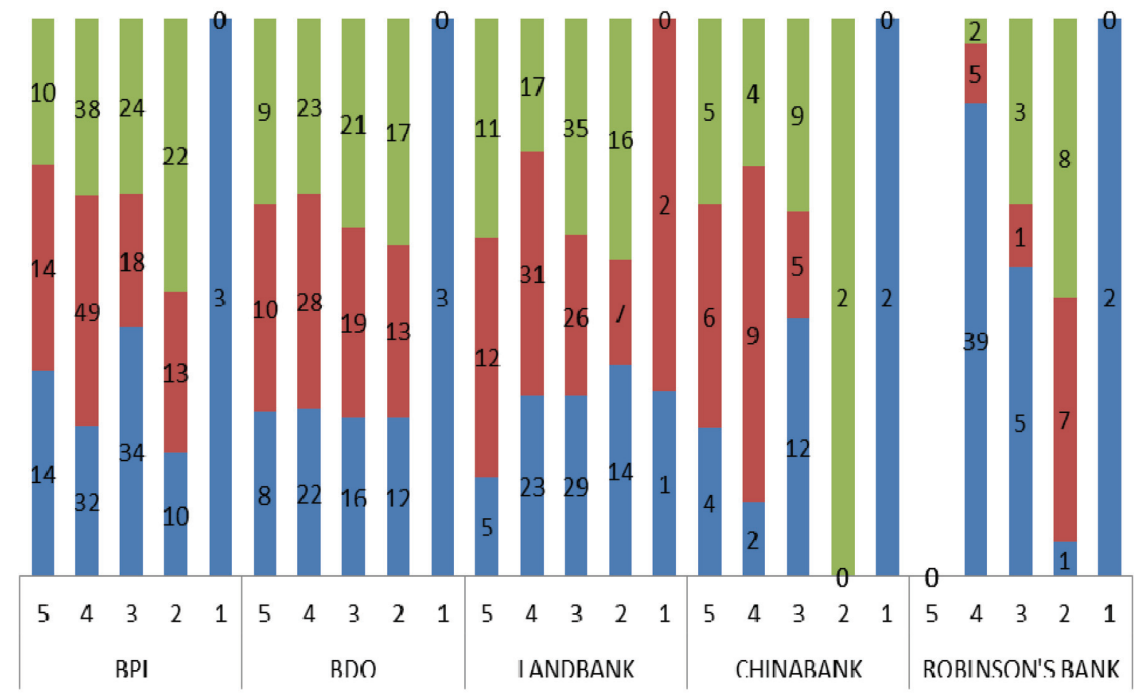

Figure 17 Error prevention.

same thing has the highest result for this factor, BPI has the highest number of respondents that agreed at the said usability problem. The system should be designed to prevent serious errors. This is the most significant factor that affects the capturing of cards among users. Users of Robinson's bank said that they were unsatisfied with the systems error prevention procedure. Error messages are not appropriate and understandable. It doesn't identify the specific problem that the user encountered and it also doesn't give clear instructions for recovery. For a system to be effective, it should have an appropriate procedure for error prevention and recovery. BDO, BPI, Landbank, and Chinabank users were neutral on their stand with regard to this factor.

Questions rated in this factor include the following: error messages identify the specific problem and give instructions for recovery, appropriate and understandable error messages are prompted and expressed in plain language when errors occur, and the system is designed to prevent serious errors. 
The stacked bar chart on Figure 18 shows the results of learnability and memorability from the five different ATMs. The information was effective in completing the tasks and scenarios have the highest result for this factor, BPI has the highest number of respondents that agreed at the said usability problem. This factor simply concentrates on the easy learning of the system for the users. Users of Robinson's bank are satisfied with the learnability and memorability of the system. BDO, BPI, Landbank, and Chinabank users were neither satisfied nor unsatisfied. Landbank has the lowest rating. It shows that the instructions and information given by the system are not effective for users' task completion. The sequence of actions and items are also hard to remember, making it hard for the users to learn how to use the system.

Questions rated in this factor include the following: it is easy to learn to use this system, the information was effective in completing the tasks and scenarios, items and action sequences are familiar and easy to remember,

\section{Learnability and Memorability}

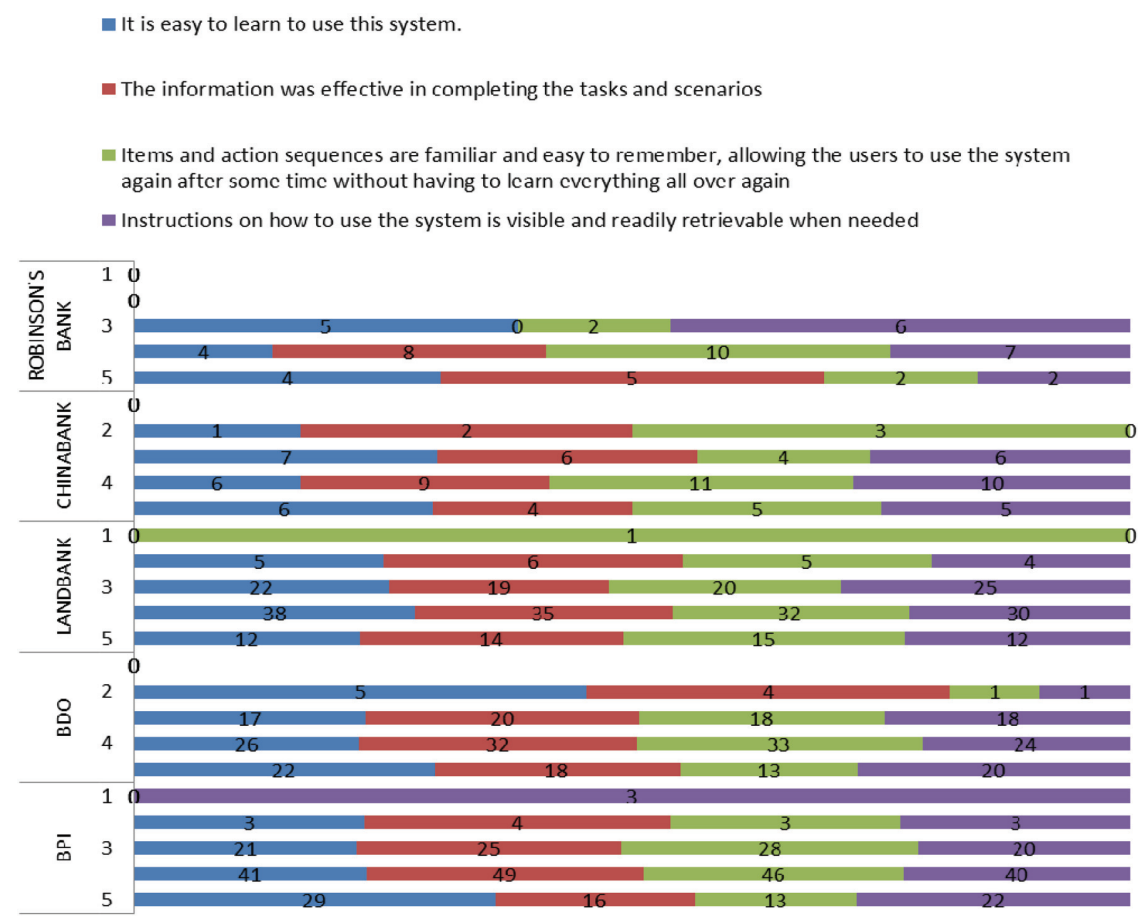

Figure 18 Learnability and memorability. 
allowing the users to use the system again after some time without having to learn everything all over again, and instructions on how to use the system is visible and readily retrievable when needed.

On Figure 19 shows the results of flexibility and efficiency of use from the five different ATMs. The system is user friendly has the highest result for this factor; BPI has the highest number of respondents that agreed, then followed by Landbank at the said usability problem. The system should cater both novice and expert users. This factor measures the system's user friendliness and efficiency. Robinson's bank has the highest rating and the BDO has the lowest. Users of all of the five banks rated neutral on this category. BDO's interface design, compare to the other banks, has the least compatibility with human's stimuli response. It is harder for the users to understand the system, especially for first time users. Shortcuts for frequent users are also not included that results to longer usage time.

Questions rated in this factor includes the following: the system caters both novice and expert users, the system is user friendly, and shortcuts are provided for frequent users of the system.

\section{Flexibility and Efficiency of use}

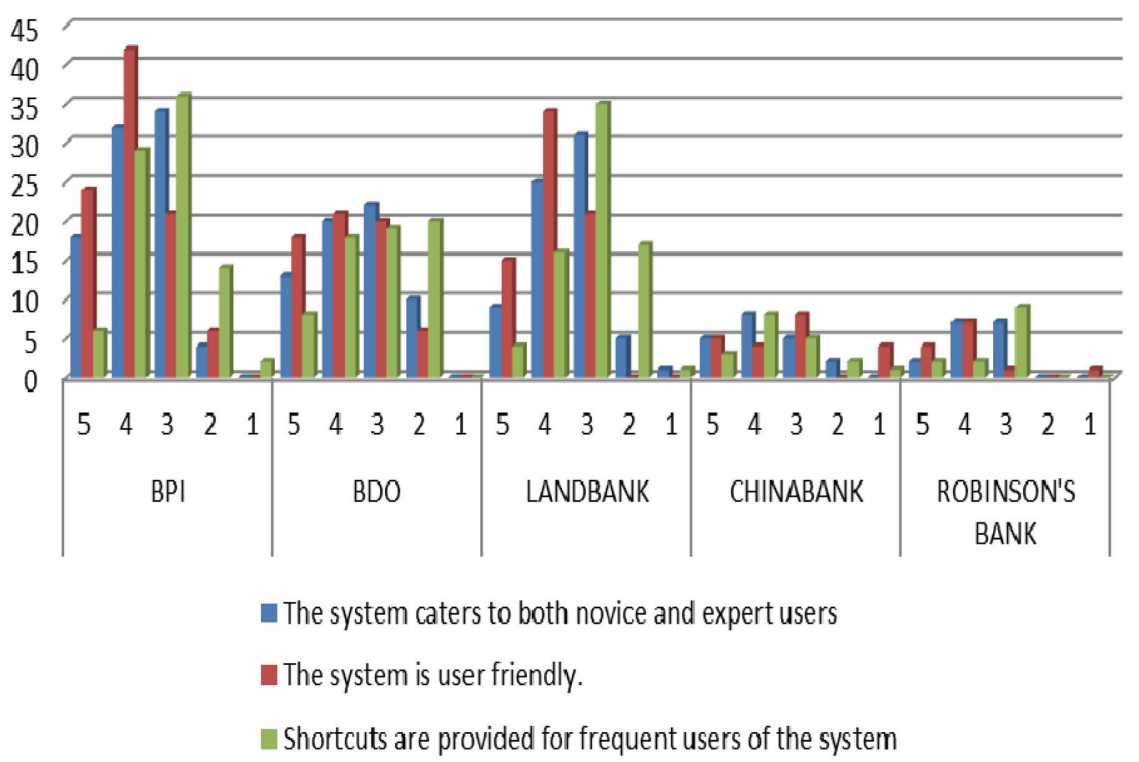

Figure 19 Flexibility. 


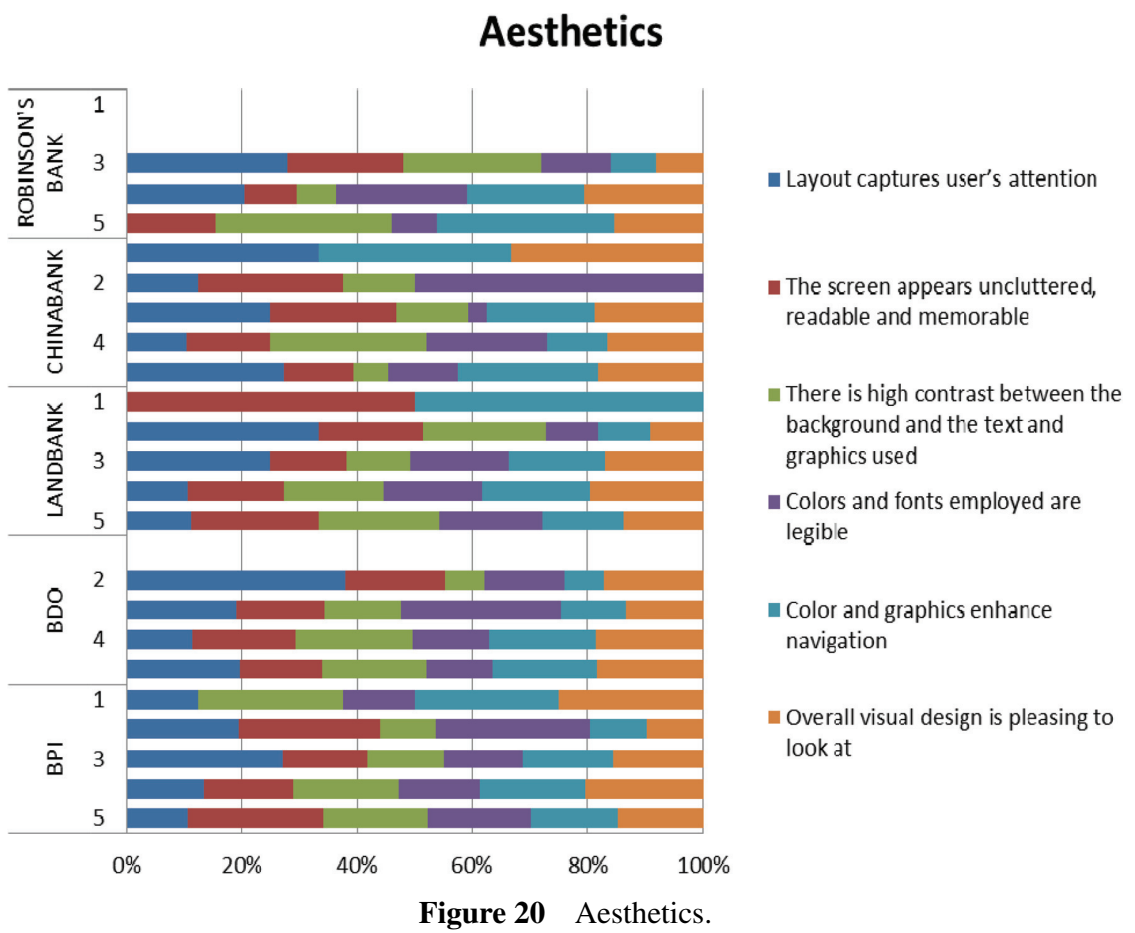

On Figure 20 shows the results of aesthetics from the five different ATMs. Overall visual design is pleasing to look at has the highest result for this factor, BPI has the highest number of respondents that agreed at the said usability factor. We can say that almost all of the users of BPI is satisfied of how the overall design of the machine looks like. The system's interface should be designed efficiently. Layout must capture user's attention. This factor sums up the overall visual design of the system. Users of the five banks studied were neither satisfied nor unsatisfied with the aesthetics of the system. Landbank has the lowest rating. The colors, fonts, graphics, backgrounds and icons of Landbanks's interface were not harmonious and compatible with each other. The screen also appears to be cluttered.

Questions rated in this factor includes the following: layout captures user's attention, the screen appears uncluttered, readable and memorable, there is a high contrast between the background and the text and graphics used, colors and fonts employed are legible, color and graphics enhance navigation, and the overall visual design is pleasing to look at. 


\subsection{ANOVA Linear Regression}

To determine which of the nine factors (visibility of the systems status and feedback on the user, meaningful labels and descriptive links, match between the system and the real world, user control and freedom, consistency, error prevention, learnability and memorability, flexibility and efficiency of use, and aesthetic) are significant in ATM usability based on customer satisfaction, ANOVA linear regression is run. The results will be discussed in this section.

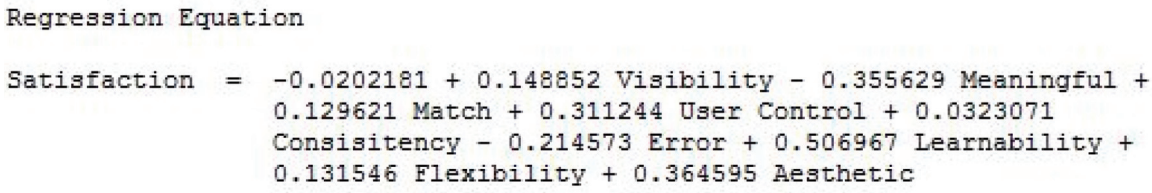

Figure 21 Regression equation for the factors affecting ATM usability.

The figure above shows the regression equation $(y=a+b x)$. ATM usability based on customer satisfaction is the dependent variable and visibility of the systems status and feedback on the user, meaningful labels and descriptive links, match between the system and the real world, user control and freedom, consistency, error prevention, learnability and memorability, flexibility and efficiency of use, and aesthetic are the independent variable.

Table 2 Summary of the fitted plot line result for the factors affecting ATM usability based on customer satisfaction

\begin{tabular}{|c|c|c|}
\hline Factor & Regression Equation & Proportionality \\
\hline $\begin{array}{l}\text { Visibility of the Systems Status and } \\
\text { Feedback on the User (Visibility) }\end{array}$ & $\begin{array}{c}\text { Satisfaction }=2.787+0.3069 \\
\text { Visibility }\end{array}$ & Directly \\
\hline $\begin{array}{l}\text { Meaningful Labels and Descriptive } \\
\text { Links (Meaningful) }\end{array}$ & $\begin{array}{c}\text { Satisfaction }=3.1183+0.2464 \\
\text { Meaningful }\end{array}$ & Directly \\
\hline $\begin{array}{l}\text { Match Between The System } \\
\text { and the Real World (Match) }\end{array}$ & Satisfaction $=2.1299+0.4734$ Match & Directly \\
\hline $\begin{array}{l}\text { User Control and Freedom } \\
\text { (User Control) }\end{array}$ & $\begin{aligned} \text { Satisfaction }= & 3.1679+0.2446 \text { User } \\
& \text { Control }\end{aligned}$ & Directly \\
\hline Consistency & $\begin{array}{c}\text { Satisfaction }=3.3969+0.1695 \\
\text { Consistency }\end{array}$ & Directly \\
\hline Error Prevention (Error) & Satisfaction $=3.8608+0.06003$ Error & Directly \\
\hline $\begin{array}{l}\text { Learnability and Memorability } \\
\text { (Learnability) }\end{array}$ & $\begin{array}{c}\text { Satisfaction }=1.4743+0.6821 \\
\text { Learnability }\end{array}$ & Directly \\
\hline $\begin{array}{l}\text { Flexibility and Efficiency } \\
\text { of Use (Flexibility) }\end{array}$ & $\begin{array}{c}\text { Satisfaction }=2.4901+0.4500 \\
\text { Flexibility }\end{array}$ & Directly \\
\hline Aesthetic & $\begin{array}{c}\text { Satisfaction }=2.2198+0.4874 \\
\text { Aesthetic }\end{array}$ & Directly \\
\hline
\end{tabular}


The nine factors namely visibility of the systems status and feedback on the user, meaningful labels and descriptive links, match between the system and the real world, user control and freedom, consistency, error prevention, learnability and memorability, flexibility and efficiency of use, and aesthetic are all directly proportional to the ATM usability based on customer satisfaction according to the graphs of the fitted plot line (see Appendix C). It means that when one of the nine factors is increasing, the ATM usability based on customer satisfaction is also increasing and vice versa.

\begin{tabular}{|c|c|c|c|c|c|c|}
\hline Term & Coef & SE Coef & I & P & $95 \%$ & $\mathrm{CI}$ \\
\hline Constant & -0.020218 & 0.868529 & -0.02328 & 0.982 & $(-1.81277$ & $1.77234)$ \\
\hline Visibility & 0.148852 & 0.208551 & 0.71375 & 0.482 & $(-0.28158$ & $0.57928)$ \\
\hline Meaningful & -0.355629 & 0.194095 & -1.83224 & 0.079 & $(-0.75622$ & $0.04496)$ \\
\hline Match & 0.129621 & 0.327563 & 0.39571 & 0.696 & $(-0.54644$, & $0.80568)$ \\
\hline User Control & 0.311244 & 0.134224 & 2.31883 & 0.029 & $(0.03422$, & $0.58827)$ \\
\hline Consisitency & 0.032307 & 0.201692 & 0.16018 & 0.874 & $(-0.38397$ & $0.44858)$ \\
\hline Error & -0.214573 & 0.141717 & -1.51410 & 0.143 & $(-0.50706$ & $0.07792)$ \\
\hline Learnability & 0.506967 & 0.227679 & 2.22668 & 0.036 & $(0.03706$, & 0.97687 ) \\
\hline Flexibility & 0.131546 & 0.169807 & 0.77468 & 0.446 & $(-0.21892$ & $0.48201)$ \\
\hline Aesthetic & 0.364595 & 0.146590 & 2.48717 & 0.020 & $(0.06205$, & 0.66714 ) \\
\hline
\end{tabular}

Figure 22 Regression analysis for the factors affecting ATM usability.

According to the regression analysis if the P-value of the predictor is greater than alpha, accept null hypothesis and reject alternative hypothesis. In contrary, if the P-value of the predictor is less than alpha, reject null hypothesis and accept alternative hypothesis. The value of alpha is 0.05 .

\section{Result of the study:}

Reject Null Hypothesis, Accept Alternative Hypothesis

Alternative Hypothesis: At least one of the factors (visibility of the systems status and feedback on the user, meaningful labels and descriptive links, match between the system and the real world, user control and freedom, consistency, error prevention, learnability and memorability, flexibility and efficiency of use, and aesthetics) has a significant effect on the effectiveness of the ATM which are associated to the customer's satisfaction. 
Table 3 Summary of the regression analysis for the factors affecting ATM usability based on customer satisfaction

\begin{tabular}{lcccc}
\hline Predictor & Coefficient & P-Value & VIF & Interpretation \\
\hline Visibility & 0.1489 & 0.482 & 2.8105 & Not Significant \\
Meaningful & -0.3556 & 0.079 & 2.1643 & Not Significant \\
Match & 0.1296 & 0.696 & 5.2964 & Not Significant \\
User Control & 0.3112 & 0.029 & 1.7881 & Significant \\
Consistency & 0.0323 & 0.874 & 1.9104 & Not Significant \\
Error & -0.2146 & 0.143 & 107803 & Not Significant \\
Learnability & 0.5069 & 0.036 & 2.1672 & Significant \\
Flexibility & 0.1315 & 0.446 & 2.1525 & Not Significant \\
Aesthetic & 0.3646 & 0.020 & 1.4106 & Significant \\
\hline
\end{tabular}

Among the nine factors, only three factors are significant which are 'User Control and Freedom', 'Learnability and Memorability', and 'Aesthetic'. It shows in the regression mode that at least one of the factors has significant effect to the dependent variable (ATM usability based on customer satisfaction), and that factor are the user control and freedom, learnability and memorability, and aesthetic. The results also shows that the values of VIF are small which indicates that there is no multicolinnearity in the model.

\begin{tabular}{|c|c|c|c|c|c|c|}
\hline $\begin{array}{l}S=0.421634 \\
\text { PRESS }=10.5832\end{array}$ & & $\begin{array}{l}q=61.3 \\
q \text { (pred) }\end{array}$ & $\begin{array}{l}98 \\
=4.23 \%\end{array}$ & R-Sq (adj) & $=46.91 \%$ & \\
\hline nalysis of $\mathrm{Va}$ & I & & & & & \\
\hline Source & $\mathrm{DF}$ & Seq SS & Adj $S S$ & Adj MS & $\mathrm{F}$ & P \\
\hline Regression & 9 & 6.7839 & 6.78394 & 0.75377 & 4.24001 & 0.002204 \\
\hline Visibility & 1 & 1.0820 & 0.09056 & 0.09056 & 0.50943 & 0.482268 \\
\hline Meaningful & 1 & 0.1717 & 0.59681 & 0.59681 & 3.35711 & 0.079354 \\
\hline Match & 1 & 0.7186 & 0.02784 & 0.02784 & 0.15659 & 0.695812 \\
\hline User Control & 1 & 1.4728 & 0.95589 & 0.95589 & 5.37697 & 0.029239 \\
\hline Consisitency & 1 & 0.2490 & 0.00456 & 0.00456 & 0.02566 & 0.874080 \\
\hline Error & 1 & 0.1715 & 0.40755 & 0.40755 & 2.29249 & 0.143061 \\
\hline Learnability & 1 & 1.7973 & 0.88143 & 0.88143 & 4.95809 & 0.035610 \\
\hline Flexibility & 1 & 0.0213 & 0.10669 & 0.10669 & 0.60013 & 0.446094 \\
\hline Aesthetic & 1 & 1.0997 & 1.09972 & 1.09972 & 6.18602 & 0.020223 \\
\hline Error & 24 & 4.2666 & 4.26662 & 0.17778 & & \\
\hline Lack-of-Fit & 23 & 4.2666 & 4.26662 & 0.18551 & * & * \\
\hline Pure Error & 1 & 0.0000 & 0.00000 & 0.00000 & & \\
\hline Total & 33 & 11.0506 & & & & \\
\hline
\end{tabular}

Figure 23 ANOVA for the factors affecting ATM usability based on customer satisfaction. 
The figure above only shows that $46.91 \%$ of the effect in ATM usability based on customer satisfaction can be explained by the significant factors, which are user control and freedom, learnability and memorability, and aesthetic.

\subsection{Queuing Theory}

The queuing model of each of the five mentioned banks (LBP, BPI, Chinabank, Robinsons bank and BDO) is also used as a predictor of the effectiveness of the ATMs. The bank with the shortest queue or has the highest servicing power is assumed to be the machine that satisfies the customers. This will also provide data that will represent the capacity of the ATM to serve its customers. In addition, the standard time of a simple transaction is also derived in this section.

\subsubsection{Standard time}

The researchers have 20 initial times for each bank of the five mentioned banks (LBP, BPI, Chinabank, Robinsons bank and BDO). A combination of balance inquiry and withdrawal were used to compute for the standard time because it has the highest frequency among the list of activities that an ATM provides. Shown on table below, is the frequency of how many exceeded the standard time for each banks.

Table 4 Exceeds standard time

\begin{tabular}{lcc}
\hline & \multicolumn{3}{c}{ Standard Time $=76.36 \mathrm{~s}$} \\
\cline { 2 - 3 } Bank & No. of Transaction that Exceeds the ST & Percentage \\
\hline BPI & 3 & $15 \%$ \\
Chinabank & 4 & $20 \%$ \\
Robinson's Bank & 5 & $25 \%$ \\
Landbank & 13 & $65 \%$ \\
BDO & 4 & $20 \%$ \\
\hline
\end{tabular}

The standard time for a customer to make a simple transaction in an ATM is 76.36 seconds. Considering that it is only a single and simple transaction and disregarding whether the customer is a novice or a frequent user. Given this standard time, the researchers classify the gathered transaction times from the five banks whether it is within or exceeds the standard time.

The table above shows that all of the banks mentioned have a transaction time that is over the standard time set by the researchers. Landbank has the highest frequency that exceeded the computed standard time, 13 out of 
20 exceeded or $65 \%$ of the sample data. It was followed by Robinson's Bank (25\%), BDO (20\%), Chinabank (20\%) and BPI (15\%). This only shows that among the five banks, Landbank of the Philippines is the least effective ATM design interface in terms of easy usage or user friendliness. A user usually spend more time when transaction in the ATM of Landbank compared to the ATMs of other banks.

\subsubsection{Infinite queue}

A queuing model is developed by the researchers to measure the capacity of each bank in terms of its ATM. A queuing process was used in the study to determine which ATM can accommodate and cannot accommodate customers in peak season (i.e. payday, Christmas season). It is assumed that for an hour in a peak season there will be 100 person who will used the ATM. An effective machine should be able to serve all those customers and perform its functions without encountering any system failure and machine breakdowns.

The model used is a steady-state infinite capacity queues. The Infinite Queue model assumes that there is no limit to the waiting line. These models give "Steady State" results. This has two important implications: the probability distributions of arrivals and service times do not change with time and the outputs are long run averages.

\begin{tabular}{lccccc}
\multicolumn{7}{c}{ Table 5 } & \multicolumn{2}{l}{ Queueing process } \\
\hline Bank & $\begin{array}{c}\text { Number } \\
\text { of } \\
\text { Servers }\end{array}$ & $\begin{array}{c}\text { Arrival } \\
\text { Rate }\end{array}$ & $\begin{array}{l}\text { Service Rate } \\
\text { Capacity of } \\
\text { Each Server }\end{array}$ & $\begin{array}{c}\text { Average No. } \\
\text { Waiting } \\
\text { in Queue }\end{array}$ & $\begin{array}{c}\text { Average } \\
\text { Waiting Time }\end{array}$ \\
\hline BPI & 1 & $100 / \mathrm{hr}$ & 124.61 & 3.26 & 0.03 \\
Chinabank & 1 & $100 / \mathrm{hr}$ & 107.37 & 12.64 & 0.13 \\
Robinson's & 1 & $100 / \mathrm{hr}$ & 126.49 & 3 & 0.03 \\
Bank & 1 & $100 / \mathrm{hr}$ & 92.64 & Error & Error \\
Landbank & 1 & $100 / \mathrm{hr}$ & 105.11 & 18.62 & 0.19 \\
BDO & 1 & & & & \\
\hline
\end{tabular}

The Table 5 shows the data that was used in the queuing model. The service rate capacity of each server, the average number of waiting in queue, and the waiting time were also identified. It is shown that the average waiting time in Landbank is labelled error, which means it cannot accommodate 100 person for an hour. It is assumed that there is something wrong with their system. BPI and Robinson's bank have the lowest average waiting time which is 0.03 hours. It is followed by Chinabank and BDO with the average waiting time of 0.13 hours and 0.19 hours, respectively. 


\subsection{Comparative Study Results}

The researchers come up with the best system design interface among the five mentioned banks - Landbank of the Philippines (LBP), Bank of the Philippine Islands (BPI), Chinabank, Robinsons bank, and Banko de Oro (BDO) based on the results of the survey on the factors affecting ATM usability based on customer satisfaction, the time that a user accumulates per transaction and the number of transactions that exceeds standard time, and the service capacity of the ATM and the average time that the customers wait for service.

Table 6 Comparative study results

\begin{tabular}{ll}
\hline First $\left(1^{\text {st }}\right)$ & Bank of the Philippine Islands (BPI) \\
\hline Second $\left(2^{\text {nd }}\right)$ & Robinsons bank \\
Third $\left(3^{\text {rd }}\right)$ & Chinabank \\
Fourth $\left(4^{\text {th }}\right)$ & Banko de Oro (BDO) \\
Fifth $\left(5^{\text {th }}\right)$ & Landbank of the Philippines (LBP) \\
\hline
\end{tabular}

The table above (Table 6) shows the result on the comparative study between the five banks mentioned earlier. The bank that ranks first (1st) among the other Automated Teller Machines (ATM) is the Bank of the Philippines Islands (BPI). The users are most satisfied in using the design interface of BPI's ATM compared to the other four banks. Therefore, it should be used as a basis in this study's recommendations. The Robinsons bank falls on the second place. It is quite near with the results of BPI. It is followed by Chinabank and Banko de Oro on the third and fourth place respectively. The ATM that needs the most improvement is the Landbank of the Philippines. As shown on the earlier results, the said bank is assumed to have a problem on their system.

\section{Recommendations and Conclusions}

\subsection{Recommendations}

After conducting a series of surveys and observations, the researchers come up with the result on the comparative study among the different Automated Teller Machines (ATMs) and its effectiveness based on customer satisfaction. The ATM interface design that excels among the rest is the Bank of the Philippines Islands (BPI) ATM. Upon identifying that, the researchers used the said bank's ATM as a basis for the recommendations.

The researchers come up with two recommendations that both solve the problem in captured cards and caters the significant factors that affect ATM 
usability based on customer satisfaction. The recommendations also aim to for better customer satisfaction.

\subsubsection{Recommended interface \#1: Touchscreen interface}

The layout of this recommendation is the same with the BPI's. Red and white is the colour used because it is clear to the eyes. A touchscreen interface is used for better user control and freedom to select the command buttons.

The figure above (Figure 24) shows the sample of the interface design that will appear once the user enters the ATM card. The command will appear on the left side of the screen in a specific sequence set by the researchers. The sequence used was based on which command is frequently used by ATM users.

Similar with the home screen, the sequence of the commands on the transaction screen (Figure 25) is based on which is frequently used by ATM users. Also, the sequence starts on the left side of the screen. In addition, the text style must be in Sans Serif point and having a height of at least 3/16 of an inch or $4.8 \mathrm{~mm}$.

To complement with the previous screen designs, the command buttons on the enter pin screen (Figure 26) is on the left side and the instruction is on the right side. Also, the key buttons is the same with what is usually used in any electronic device to enhance the learnability and memorability on the usage of the machine.

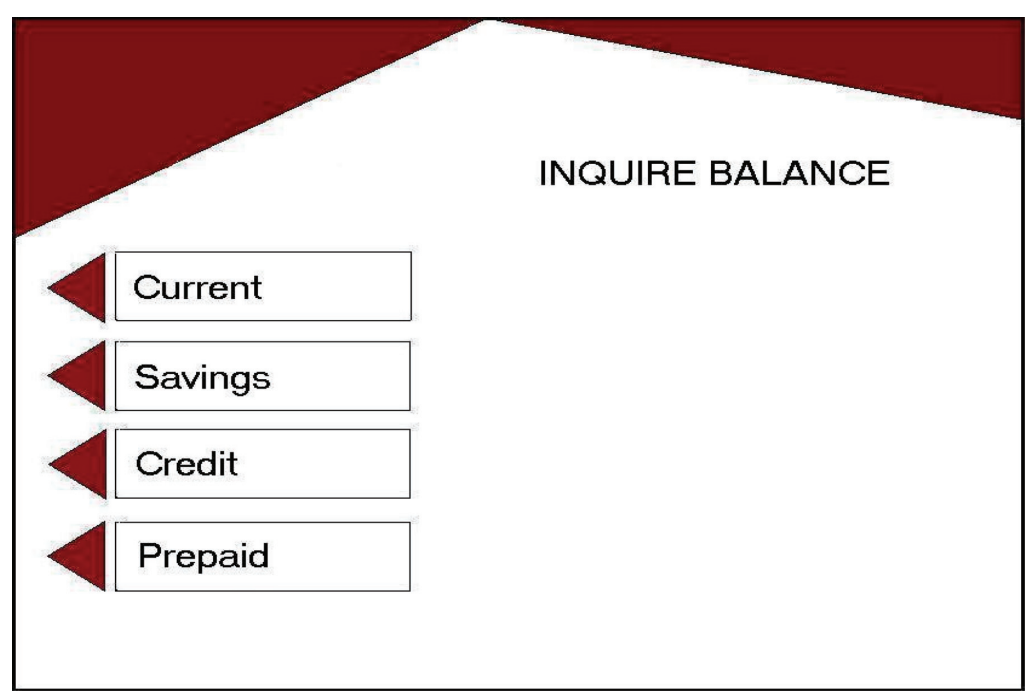

Figure 24 Home screen. 
Text style must be in Sans Serif point, having a height of at least $3 / 16$ of an inch $(4.8 \mathrm{~mm})$, based on the letter "I"

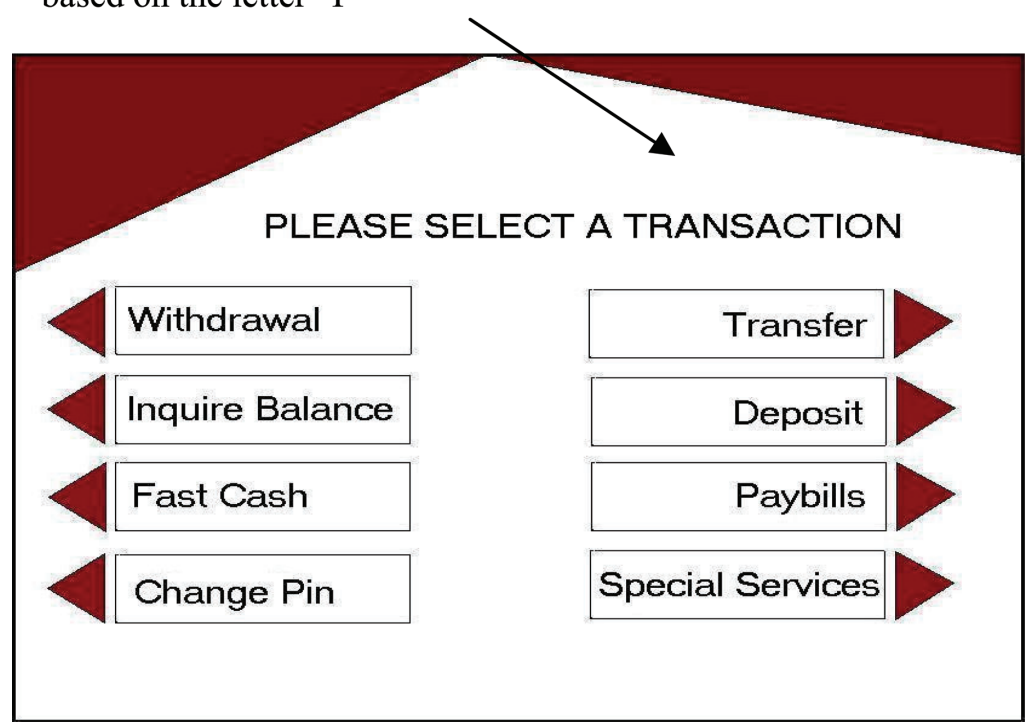

Figure 25 Transaction screen.

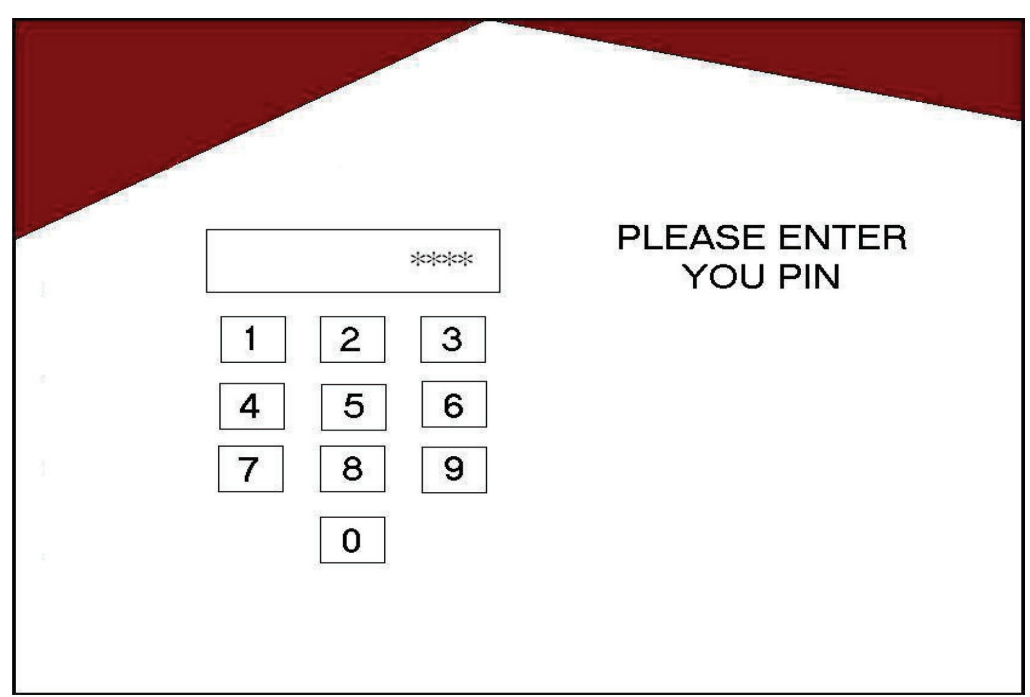

Figure 26 Enter pin screen. 


\subsubsection{Recommended interface \# 2: ATM interface with speech output and keypad}

The second recommendation is a voice command ATM. Voice commands makes it easier for a user to control the system. Instead of selecting the buttons, the users now just have to speak the command, which takes a less effort. It could be a little risky in terms to privacy but it makes the transactions much easier and faster.

The layout of the screen is the same with the first recommendation. One of the difference is the command button, which are tactile. It is also embossed to help users identify the proper command buttons needed to selected.

Table 7 shows the problems encountered and additional specifications for proposing new interfaces for an ATM. The table also shows the supporting studies which served as guidelines in proposing new designs.

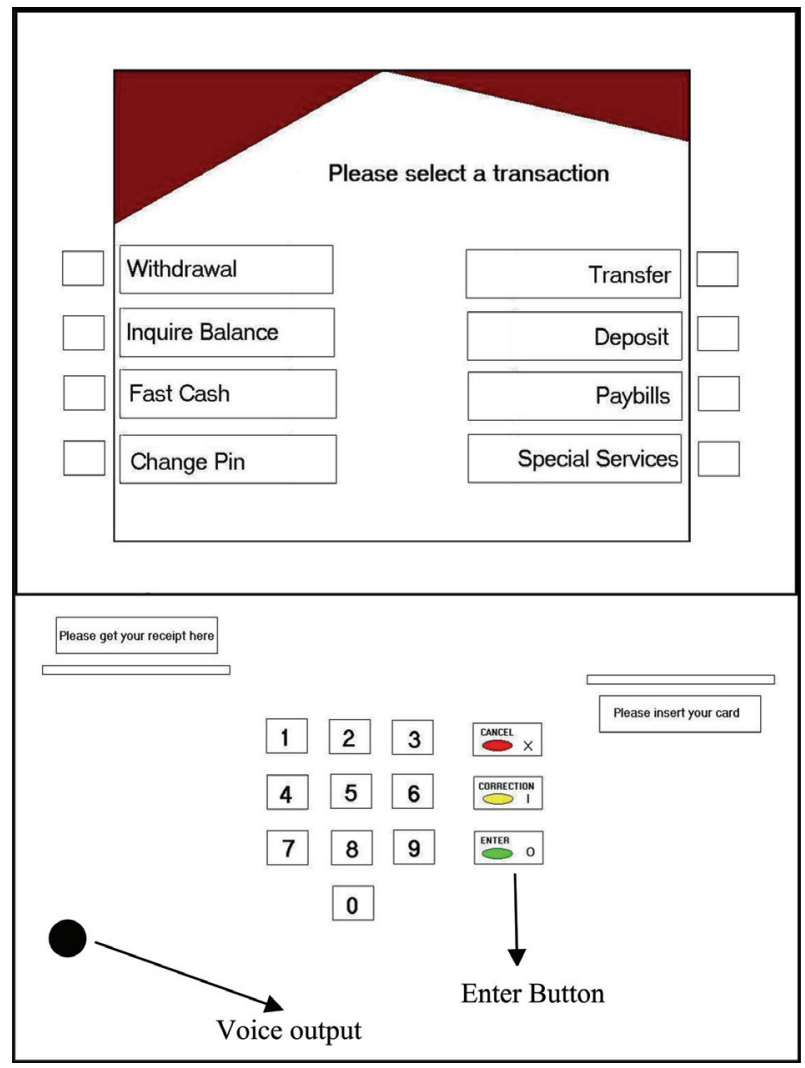

Figure 27 Voice command ATM interface design. 
A Comparative Study of Different Automated Teller Machine

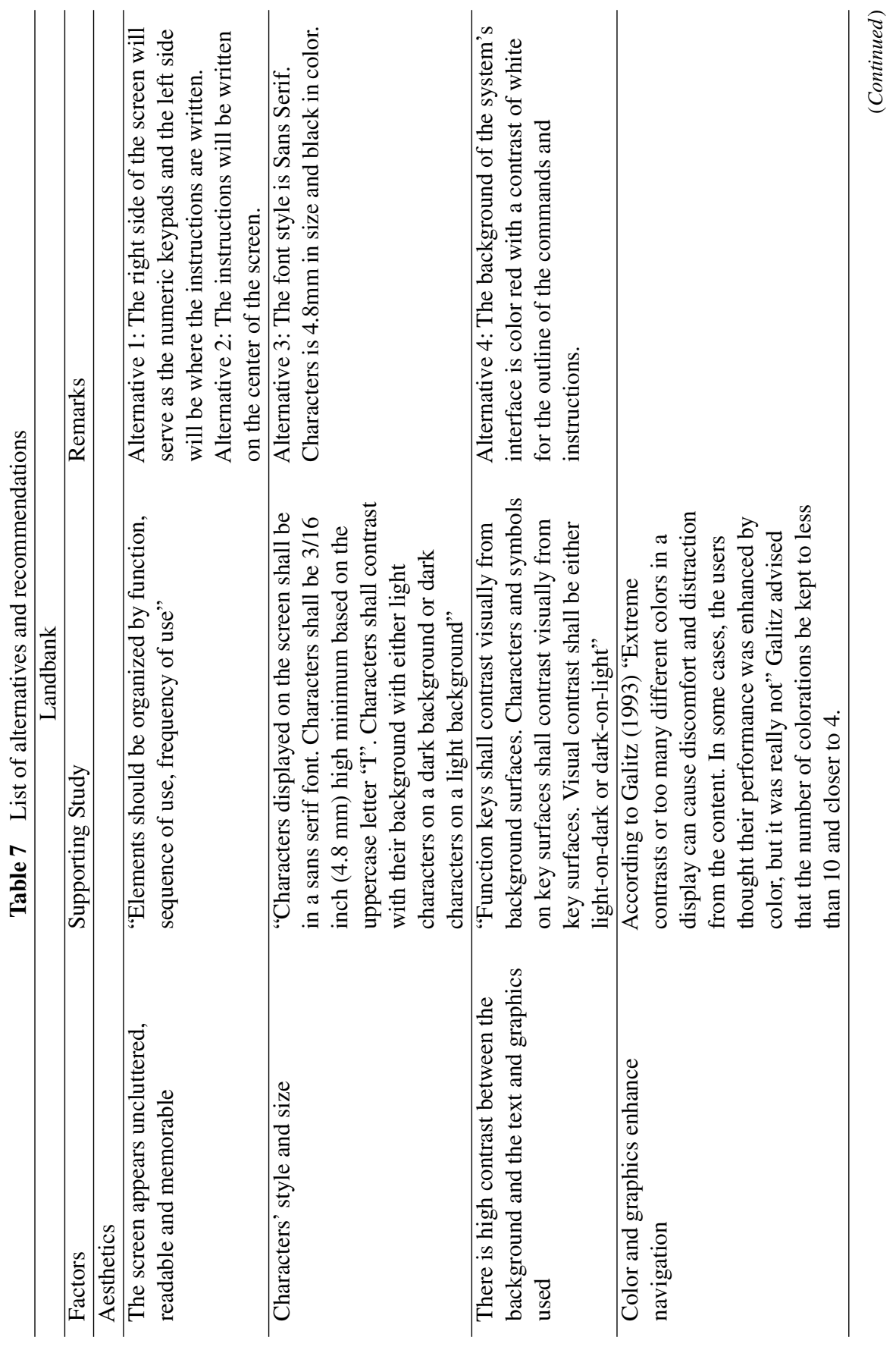


86 M. B. Calayag et al.

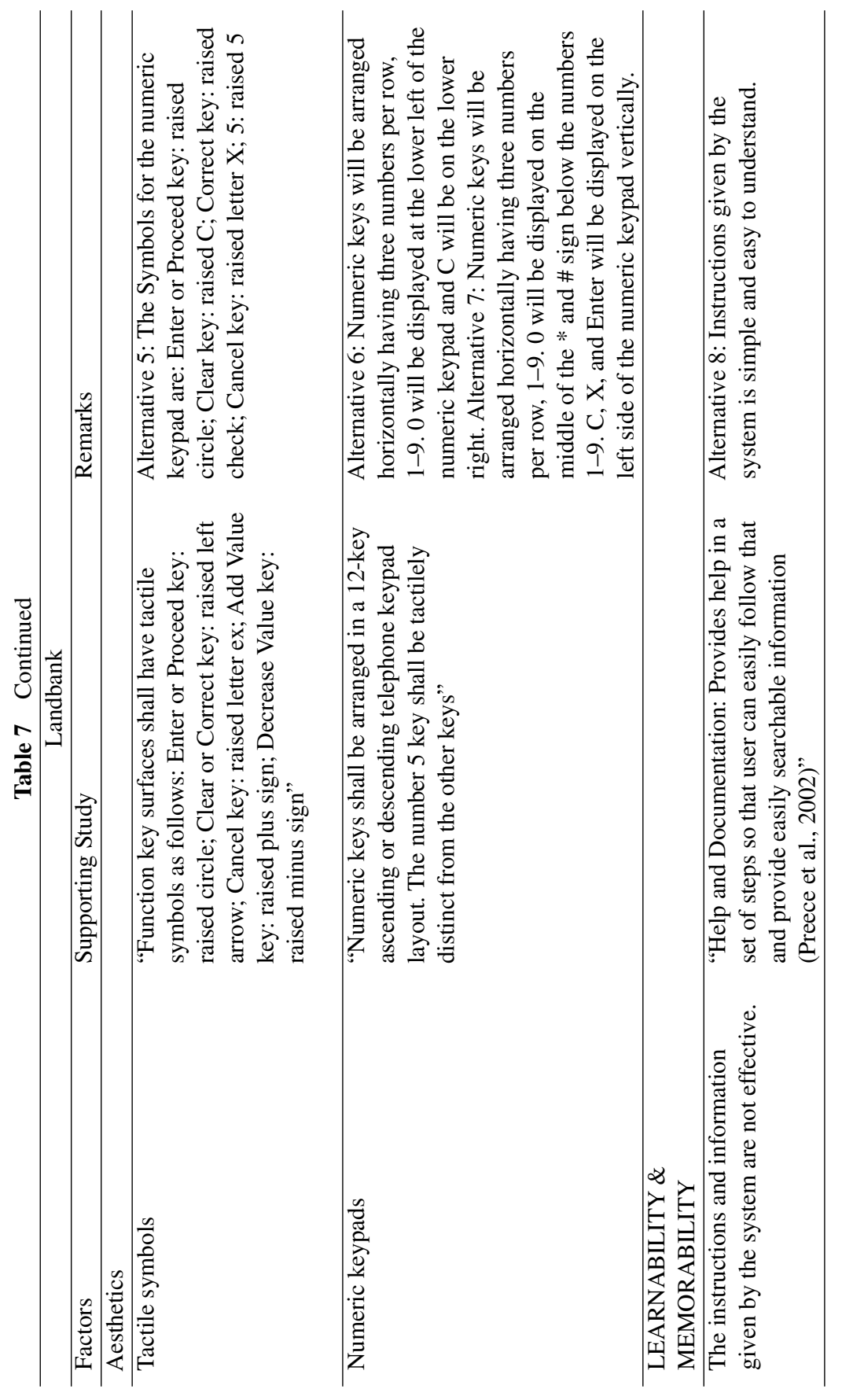




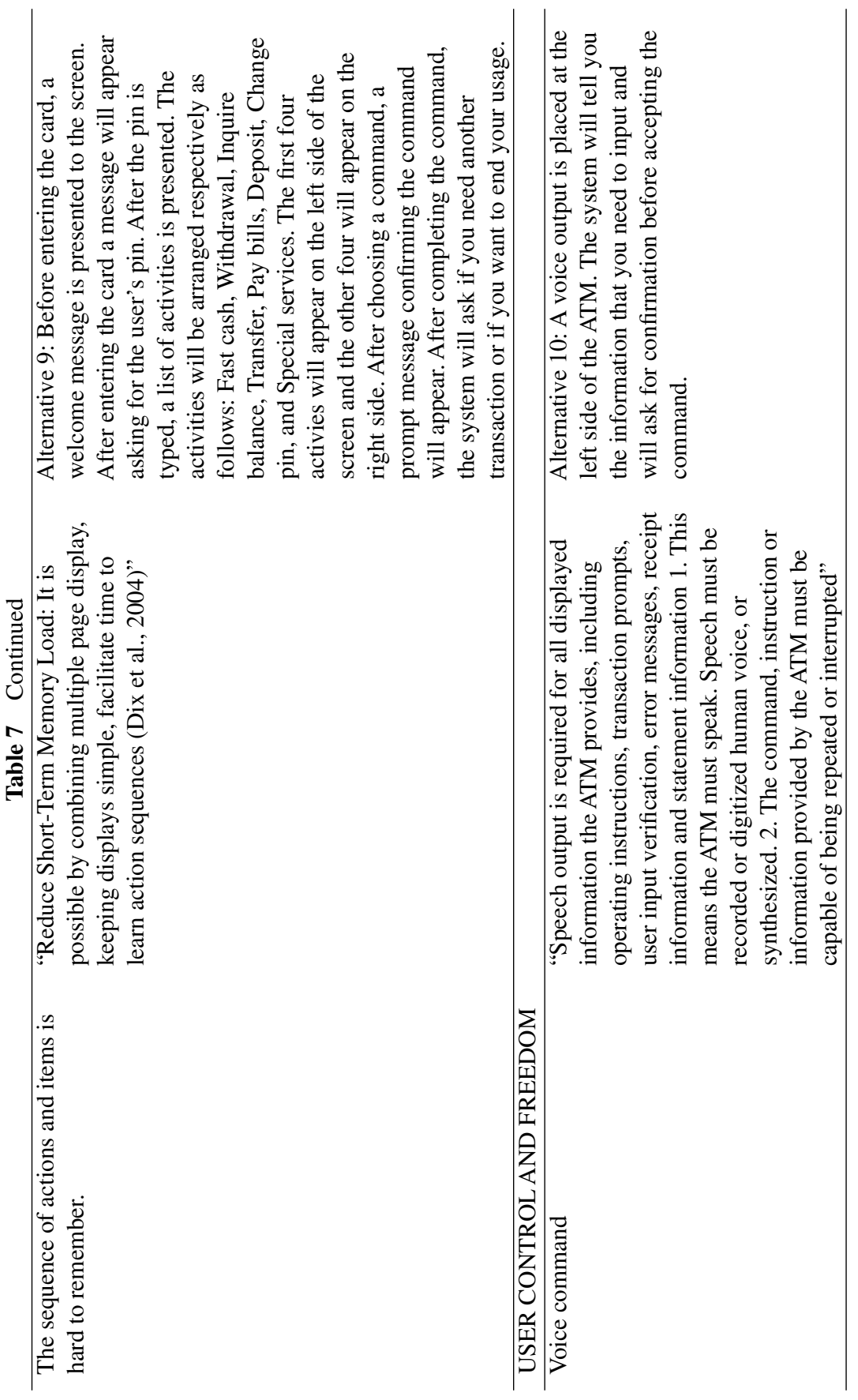


The researchers used the standards announced by the Department of Justice in America, which included the final ruling regarding ADA Standards for Accessible Design, which was published in the Federal Register September 15,2010 . These standards specify requirements for accessibility and usability for ATMs, the rules was strictly implemented for customers and customers with disabilities. These standards were used by the researchers on designing and proposing new interfaces.

To develop the best recommendation among the alternatives, the researchers used a criteria implemented in the First Data Corporation. There are five factors on the said criteria, which are functionality (25\%), accessibility (25\%), Security (20\%), user interaction (25\%), and customization $(5 \%)$ for a total of $100 \%$. Functionality focuses on whether the ATM was able to serve its purpose properly. The machine should perform its basic functions like balance inquiry, withdrawal, and many more. Accessibility focuses on its ability on easy use and understanding. Whether the customers are novice or frequents users, ATM should be accessible to anyone. Security focuses on the privacy risk in using the system. An ATM is a sensitive device in terms of privacy, so it is important to develop a designed that will cater this problem. User interaction and customizations is a big factor for customer satisfaction. This involves the users control on the functions of the machine, the freedom to customize the desired interface, and the aesthetic used on the design interface.

The researchers rated the five criteria subjectively depending on their own perspective. After evaluating each alternatives, the best recommendation is the ATM interface with speech output and keypads. Voice commands makes it easier for a user to control the system. Instead of selecting the buttons, the users now just have to speak the command, which takes a less effort. It could be a little risky in terms to privacy but it makes the transactions much easier and faster.

Table 7 Criteria

\begin{tabular}{lll}
\hline & Touch Screen Interface & $\begin{array}{l}\text { ATM Interface with Speech } \\
\text { Output and Keypads }\end{array}$ \\
\hline Functionality (25\%) & $21 \%$ & $21.33 \%$ \\
Accessibility (25\%) & $20.33 \%$ & $23 \%$ \\
Security (20\%) & $18 \%$ & $15.33 \%$ \\
User Interaction (25\%) & $20 \%$ & $23 \%$ \\
Customization (5\%) & $3.33 \%$ & $3.33 \%$ \\
Total & $82.66 \%$ & $85.99 \%$ \\
\hline
\end{tabular}




\section{Conclusions}

Automated Teller Machine is a device used by bank customers to make a basic transaction like withdrawing money, checking balance account without the help of any bank teller. In this study, researchers analyse the human-computer interaction and usability evaluation of five different automated teller machine in which banks use different interface design to develop an ergonomically design interface.

Based on the data gathered by the researchers, Landbank has the lowest results in survey, time study and queueing process among the other banks. The said data are used to find which factors affect the interaction of human and ATMs and these are; user control and freedom, aesthetics and learnability and memorability. With these factors the researchers focus on those to develop new design interfaces. In regards with these factors, the researchers recommended the automated teller machine interface with speech output and keypads over the touchscreen interface. With the help and knowledge of the researchers about ADA Standards for Accessible Design, which set standards on creating the proper ATM interface, which aims for better usability and accessibility for all the users, including people with disabilities pushed the researchers on choosing the first recommended interface. Using the alternatives that the researchers develop and through this recommendation, the automated teller machine design interface will be more accessible, user friendly and usable especially for disabled person.

\section{Appendices}

\section{Appendix A: Survey Questionnaire}

\section{HUMAN-COMPUTER INTERACTION AND USABILITY EVALUATION (ATM)}

This survey is used to study the problems encountered by customers in using ATMs and the rate of satisfaction they can give after using the said machine and also for the assistance of the students in connection to their studies. (Kindly check the box that corresponds to your answer. Thank you!)

Name (optional):

Age:

Gender: 
90 M. B. Calayag et al.

Part I. Familiarization

In which ATM do you usually transact? (check at least 3)

$\square$ BDO $\square$ BPI $\square$ Chinabank $\square$ Landbank $\square$ Robinson's Bank

Have you encountered your ATM card captured by the machine?

$\square$ YES $\square$ NO

If YES, in what bank?

\section{$\square$ BDO $\square$ BPI $\square$ Chinabank $\square$ Landbank $\square$ Robinson's Bank}

List of activities done:

$\square$ Balance Inquiry $\quad \square$ Withdrawal

$\square$ Transfer Funds $\quad \square$ Cash Advance

$\square$ Checkbook Recorder $\quad \square$ Fast Cash

$\square$ Bills Payment

Others

Part II. Usability Evaluation Checklist

Please use the following scale to identify usability problems of the ATM/s you have used.

\begin{tabular}{ll}
\hline Code & Interpretation \\
\hline 5 & Strongly Agree \\
4 & Agree \\
3 & Neutral \\
2 & Disagree \\
1 & Strongly Disagree \\
\hline
\end{tabular}




\begin{tabular}{|l|l|l|l|l|l|}
\hline \multicolumn{1}{|c|}{ BPI } & BDO & $\begin{array}{c}\text { LAND } \\
\text { BANK }\end{array}$ & $\begin{array}{c}\text { CHINA } \\
\text { BANK }\end{array}$ & $\begin{array}{c}\text { RO B } \\
\text { BANK }\end{array}$ \\
\hline \multicolumn{1}{|c|}{ Visibility of the system status and Feedback on the user } \\
\hline $\begin{array}{l}\text { Related information or } \\
\text { options are logically } \\
\text { grouped and labeled }\end{array}$ & & & & & \\
\hline \multicolumn{1}{|c|}{ Meaningful labels and descriptive links are used to support } \\
recognition
\end{tabular}


92 M. B. Calayag et al.

\begin{tabular}{|l|l|l|l|l|l|}
\hline \multicolumn{1}{|c|}{ Consistency and adherence to standards } \\
\hline
\end{tabular}




\begin{tabular}{|c|c|c|c|c|c|}
\hline & BPI & BDO & \begin{tabular}{|l|} 
LAND \\
BANK \\
\end{tabular} & \begin{tabular}{|l|} 
CHINA \\
BANK \\
\end{tabular} & \begin{tabular}{|l|} 
ROB \\
BANK \\
\end{tabular} \\
\hline \multicolumn{6}{|c|}{ Flexibility and Efficiency of use } \\
\hline $\begin{array}{l}\text { The system } \\
\text { caters to both } \\
\text { novice and } \\
\text { expert users }\end{array}$ & & & & & \\
\hline $\begin{array}{l}\text { The system is } \\
\text { user friendly. }\end{array}$ & & & & & \\
\hline $\begin{array}{l}\text { Shortcuts are } \\
\text { provided for } \\
\text { frequent users of } \\
\text { the system }\end{array}$ & & & & & \\
\hline \multicolumn{6}{|c|}{ Aesthetics } \\
\hline \multicolumn{6}{|l|}{$\begin{array}{l}\text { Layout captures } \\
\text { user's attention }\end{array}$} \\
\hline \multicolumn{6}{|l|}{$\begin{array}{l}\text { The screen } \\
\text { appears } \\
\text { uncluttered, } \\
\text { readable and } \\
\text { memorable }\end{array}$} \\
\hline $\begin{array}{l}\text { There is high } \\
\text { contrast between } \\
\text { the background } \\
\text { and the text and } \\
\text { graphics used }\end{array}$ & & & & & \\
\hline \multicolumn{6}{|l|}{$\begin{array}{l}\text { Colors and fonts } \\
\text { employed are } \\
\text { legible }\end{array}$} \\
\hline \multicolumn{6}{|l|}{\begin{tabular}{|l|} 
Color and \\
graphics enhance \\
navigation
\end{tabular}} \\
\hline $\begin{array}{l}\text { Overall visual } \\
\text { design is pleasing } \\
\text { to look at }\end{array}$ & & & & & \\
\hline \multicolumn{6}{|c|}{ Satisfaction } \\
\hline $\begin{array}{l}\text { The user is } \\
\text { satisfied with the } \\
\text { use of this } \\
\text { system }\end{array}$ & & & & & \\
\hline $\begin{array}{l}\text { The interface of } \\
\text { the system was } \\
\text { pleasant }\end{array}$ & & & & & \\
\hline
\end{tabular}




\section{Appendix B: Average Rating of the Factors Affecting System's Usability}

\begin{tabular}{lccccc}
\hline & & & $\begin{array}{l}\text { LAND } \\
\text { BANK }\end{array}$ & $\begin{array}{l}\text { CHINA } \\
\text { BANK }\end{array}$ & $\begin{array}{l}\text { ROB } \\
\text { BANK }\end{array}$ \\
\hline $\begin{array}{l}\text { Visibility of the system status and } \\
\begin{array}{l}\text { Feedback on the user } \\
\text { Meaningful labels and descriptive links } \\
\text { are used to support recognition }\end{array}\end{array}$ & 4.23 & 4.13 & 4.07 & 3.87 & 4.5 \\
\hline $\begin{array}{l}\text { Match between the system and the real } \\
\text { world }\end{array}$ & 4.09 & 4.99 & 3.76 & 3.77 & 3.63 \\
\hline User control and freedom & 3.64 & 3.75 & 3.44 & 3.68 & 3.53 \\
\hline Consistency and adherence to standards & 3.99 & 3.91 & 3.80 & 3.97 & 3.43 \\
\hline Error prevention & 3.53 & 3.59 & 3.34 & 3.65 & 2.85 \\
\hline Learnability and Memorability & 3.95 & 3.93 & 3.86 & 3.94 & 4.15 \\
\hline Flexibility and Efficiency of use & 3.67 & 3.52 & 3.55 & 3.76 & 3.83 \\
\hline Aesthetics & 3.77 & 3.77 & 3.69 & 3.72 & 3.83 \\
\hline Satisfaction & 3.98 & 3.94 & 3.95 & 3.5 & 4.33 \\
\hline Overall Rating & 3.878 & 3.86 & 3.743 & 3.777 & 3.773 \\
\hline
\end{tabular}

\section{Appendix C: Fitted Plot Line}

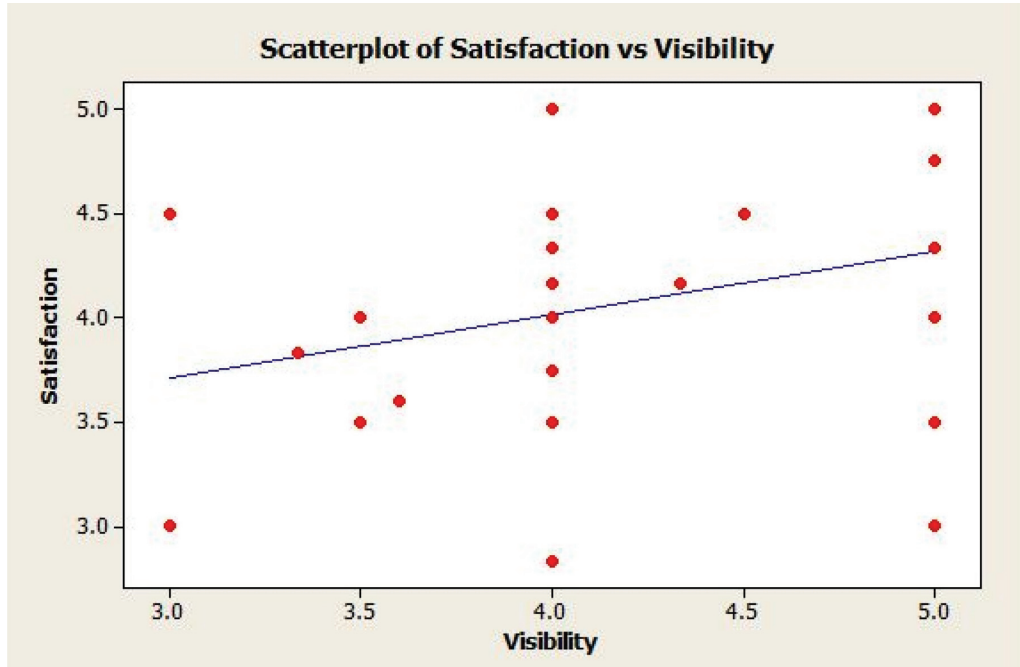

Figure 28 Fitted Plot Line of Customer Satisfaction versus Visibility of the System Status and Feedback on the user. 


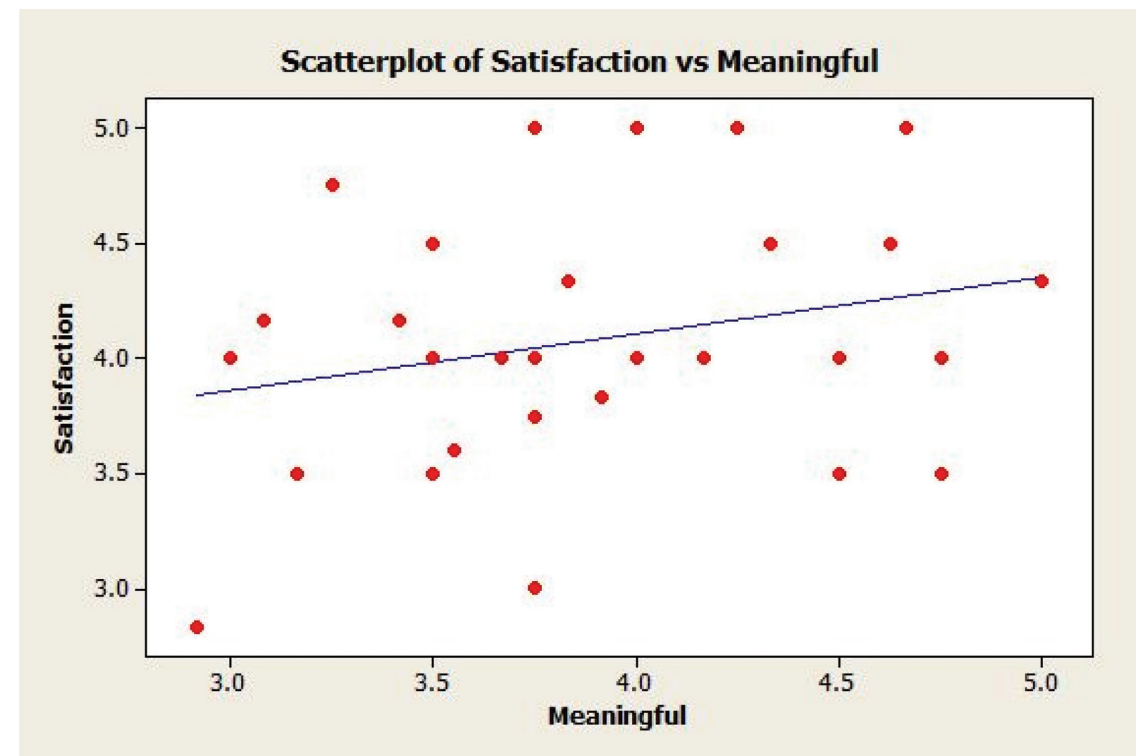

Figure 29 Fitted Plot Line of Customer Satisfaction versus Meaningful labels and descriptive links are used to support recognition.

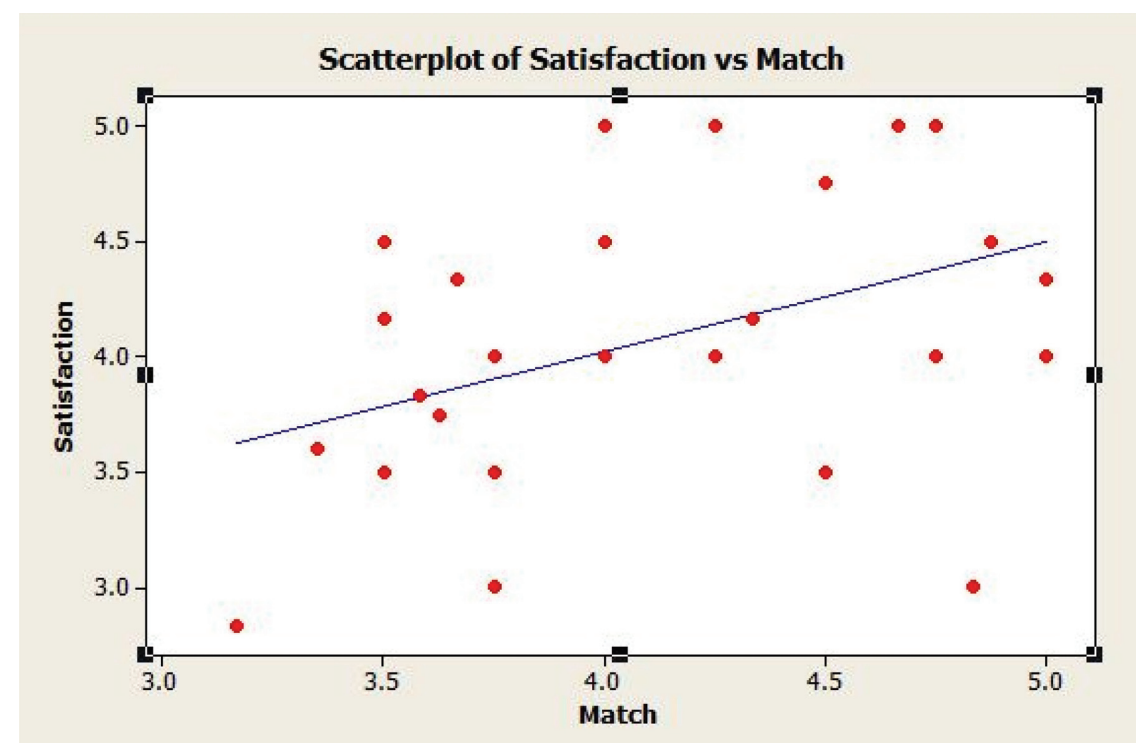

Figure 30 Fitted Plot Line of Customer Satisfaction versus Match between the System and the Real World. 


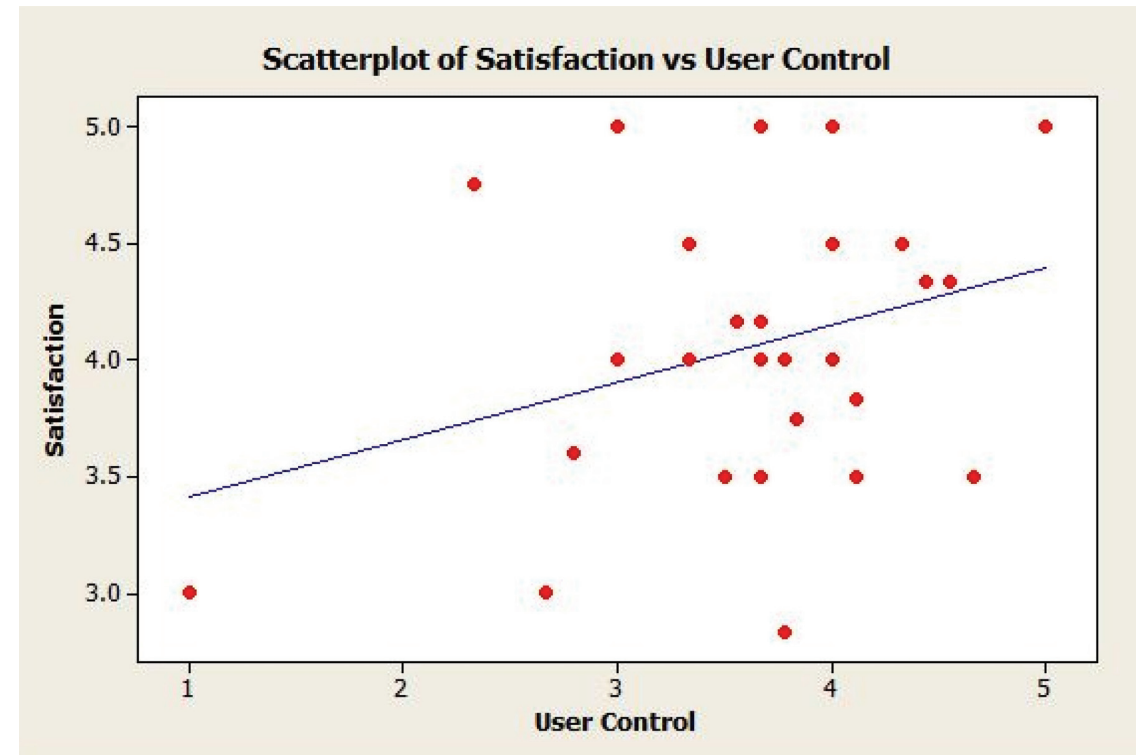

Figure 31 Fitted Plot Line of Customer Satisfaction versus User control and Freedom.

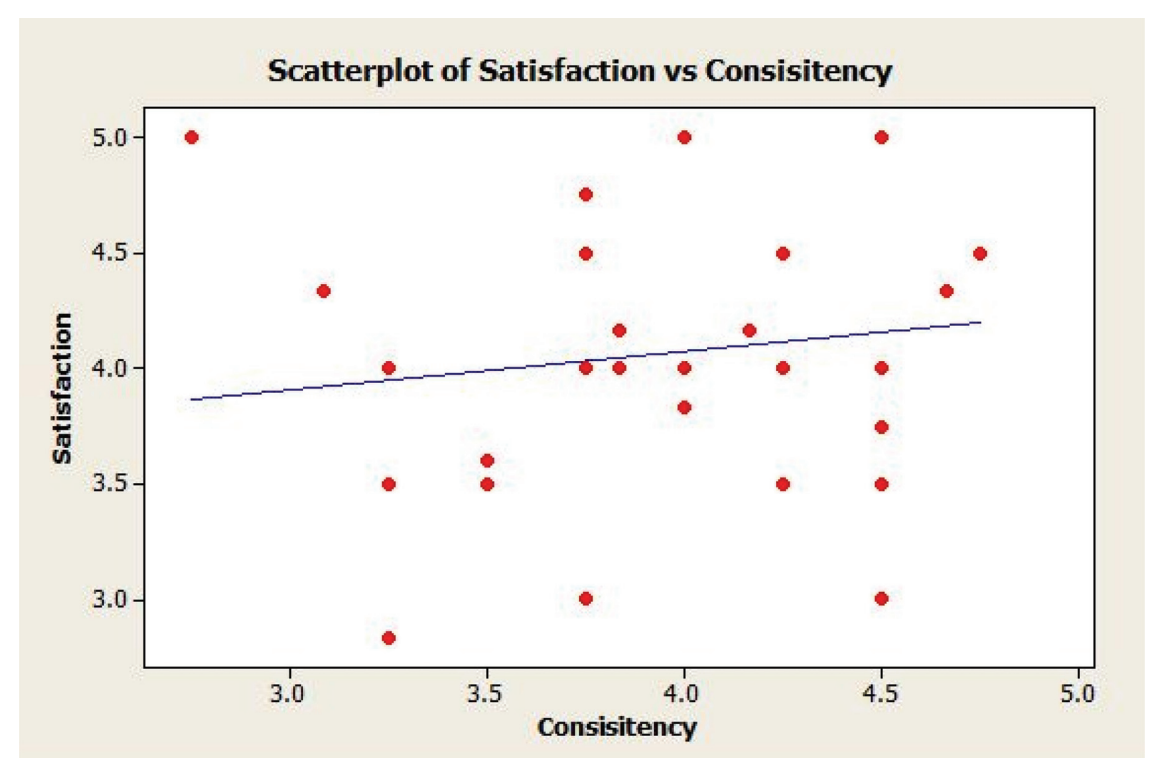

Figure 32 Fitted Plot Line of Customer Satisfaction versus Consistency and Adherence to Standards. 


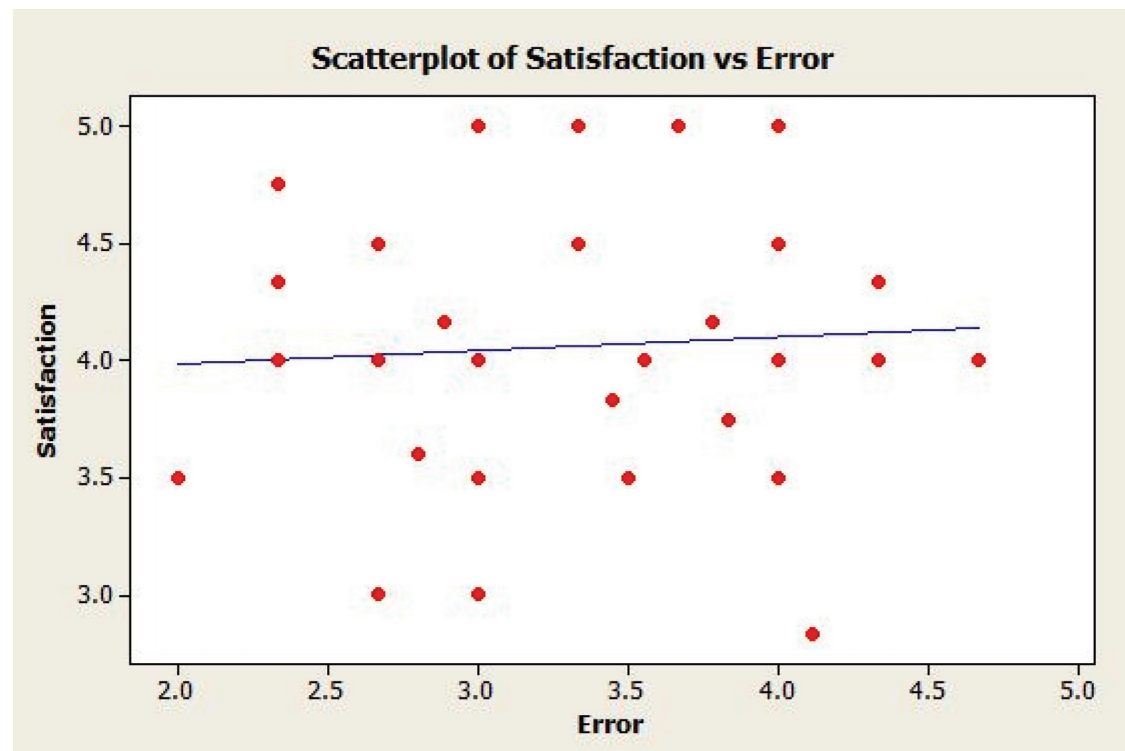

Figure 33 Fitted Plot Line of Customer Satisfaction versus Error prevention.

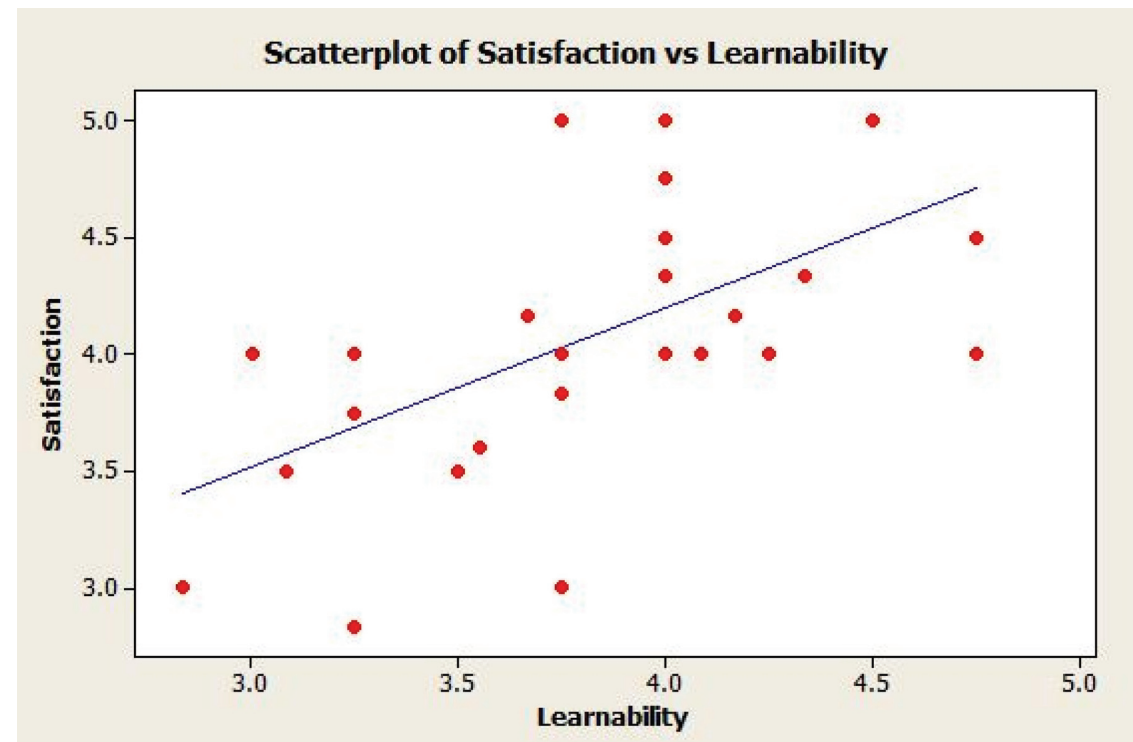

Figure 34 Fitted Plot Line of Customer Satisfaction versus Learnability and Memorability. 


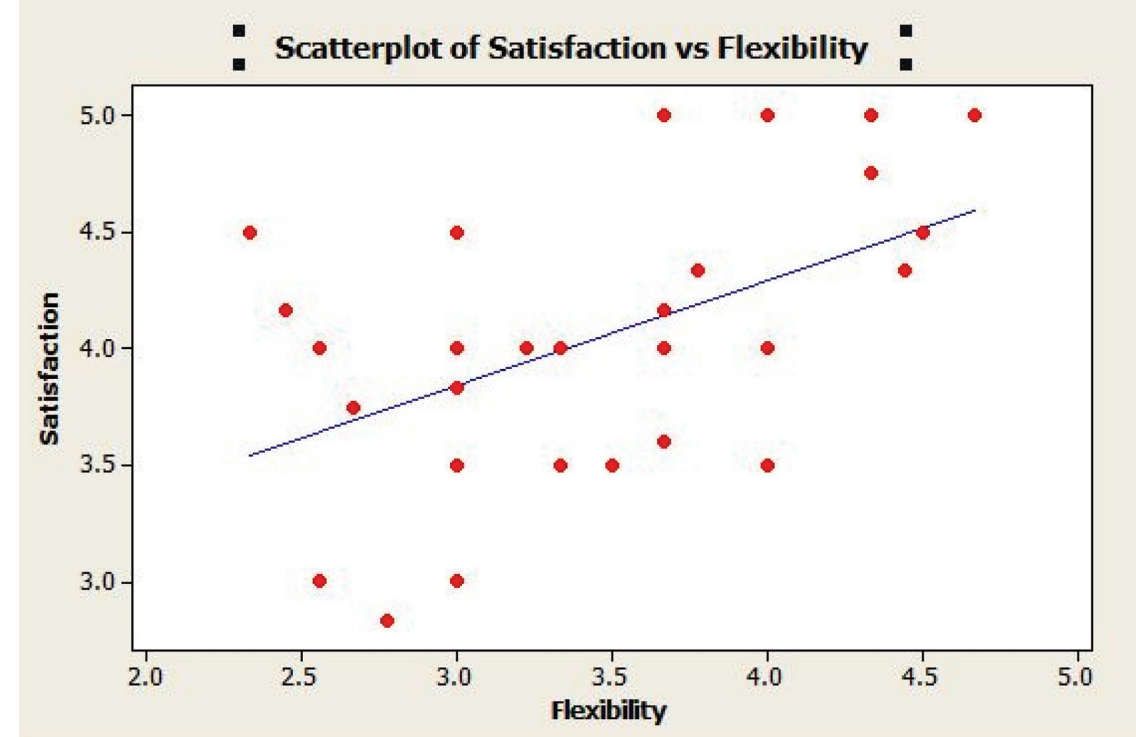

Figure 35 Fitted Plot Line of Customer Satisfaction versus Flexibility and Efficiency of use.

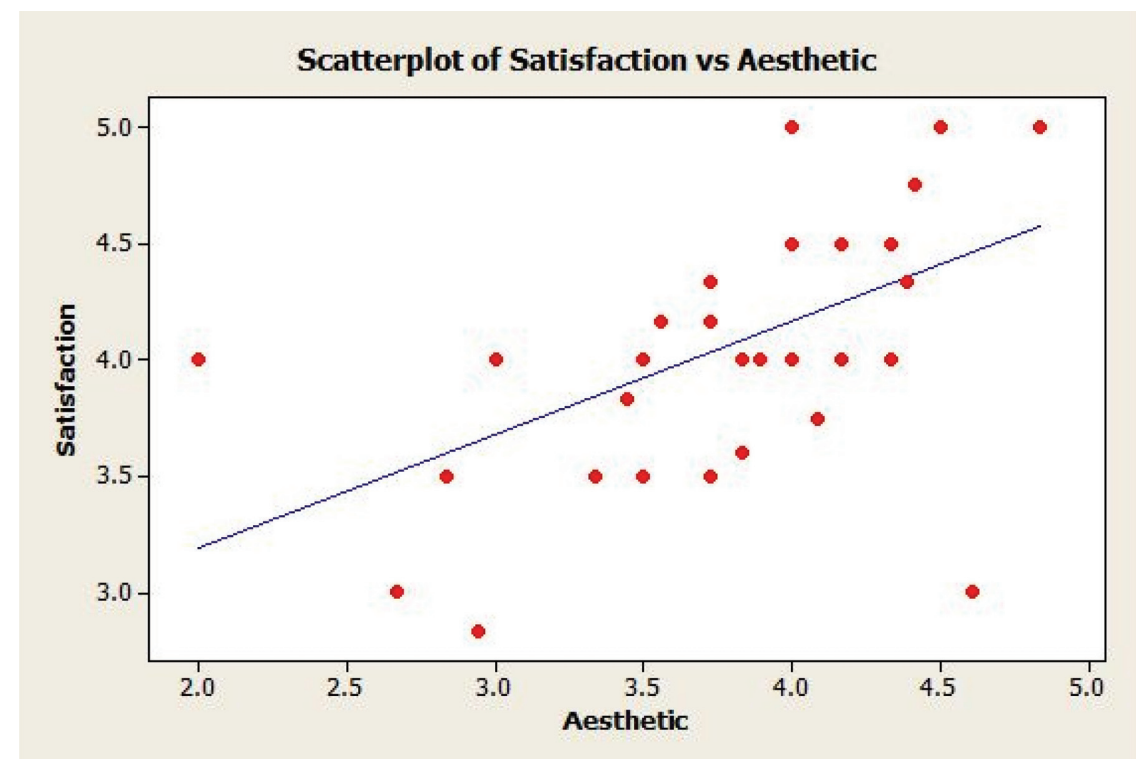

Figure 36 Fitted Plot Line of Customer Satisfaction versus Aesthetics. 


\section{Acknowledgment}

The researchers would like to express their deepest gratitude and appreciation to the following people who contributed to the completion of this research. They could never have accomplished this task without them.

The adviser for Human Factors Ergonomics, Engr. Marianne Calayag, for helping the researchers develop their study and for her incessant support that pushes the researchers to do their best.

The Industrial Engineering Department of Bulacan State University, to their friends, and to their family. The protection and guidance of God.

\section{References}

[1] Helander, M. (2005). A Guide to Human Factors and Ergonomics, 2nd Edn. Boca Raton, FL: CRC Press.

[2] Automated teller machines (ATMs) (per 100,000 adults) in Philippines (2013). Tradingeconomics Homepage. Available at: http://www.trading economics.com/philippines/automated-teller-machines-atms-per-100000-adults-wb-data.html

[3] ATMs introduced in $\mathrm{PH}$ in 1980s (2013). Inquirer.net Homepage on Newsinfo. [Online]. Available at: http://newsinfo.inquirer.net/355043/ atms-introduced-in-ph-in-1980s

[4] Adeniran, L. R., and Junaidu, A. S. (2014). An empirical study of automated teller machine (ATM) and user satisfaction in Nigeria: a study of United Bank for Africa in Sokoto metropolis. Int. J. Manag. Technol. 2, 1-11.

[5] Zhang, M., Wang, F., Deng, H., and Yin, J. (2013). A survey on human computer interaction technology for ATM. Int. J. Intel. Eng. Syst. 6.

[6] United States Department of Justice (2010). ADA Standards for Accessible Design. Washington, DC: United States Department of Justice.

[7] Idris, B. (2014). "Customer Satisfaction of Automated Teller Machine (ATM) Based on Service Quality," in Proceedings of The 2014 WEI International Academic Conference, New Orleans, LA.

[8] Islam, T. (2015). Customers' satisfaction and ATM services: the case of Bangladesh. World Rev. Bus. Res. 5, 121-139.

[9] Lakshmi, R. S., and Kavitha, P. (2013). Customer satisfaction in ATM services: a study with the reference to Indian Bank at Tiruchirappalli corporation. Int. J. Manag. Focus 1-9.

[10] Mwatsika, C. (2016). Factors influencing customer satisfaction with ATM banking. Int. J. Acad. Res. Bus. Soc. Sci. 6. 


\section{Biographies}

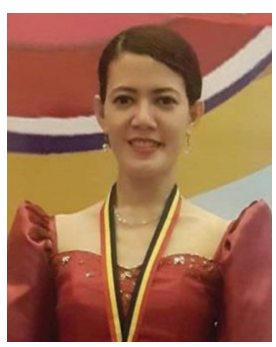

M. B. Calayag is an ASEAN and Professional Industrial Engineer. She earned her Master of Science in Manufacturing Engineering in Bulacan State University, Philippines and her Bachelor of Science in Industrial Engineering in Mapua Institute of Technology, Philippines. She is a full time faculty for eleven years. She also worked as an Analyst in a Data Processing Industry for two years. She presented several researches in local and international fora.

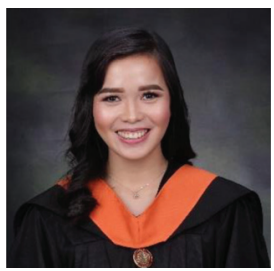

D. M. M. Regala finished her Bachelor's Degree in Industrial Engineering at Bulacan State University (Main Campus) from the pearl of the orient seas, Philippines on the year 2017. She was born on September 15, 1995 and raised by her loving parents and two sisters in the city of Malolos, Bulacan. She grew with good influences around her, including her auntie, who inspired her to also become an Industrial Engineer. She also enjoys studying the field of Ergonomics and plans on focusing on this field on her future works as an IE. 


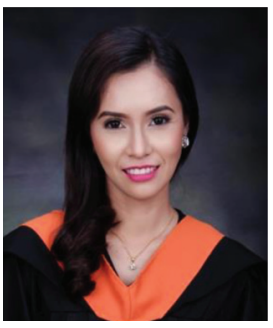

C. J. R. Rivera lives in Angat, Bulacan, Philippines and born on September 18, 1995. She has three sisters and two brothers. She studied Industrial Engineering at Bulacan State University (Main Campus), Philippines on the year 2017. From there, she hopes to take a Master's Degree in Industrial Engineering one day.

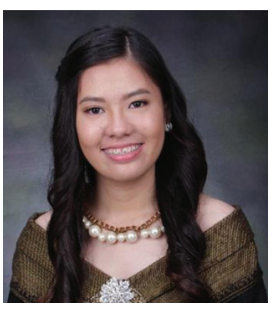

D. M. N. Tancio was born on September 5, 1996 and raised on the city of Malolos, Bulacan, Philippines. She received her Bachelor's Degree in Industrial Engineering from Bulacan State University (Main Campus), Philippines on the year 2017. She was a DOST-SEI scholar which helps her finance her academic needs. At Bulacan State University, she was a member of IEntelligent, an organization that participates on quiz show competitions, and earned her team Championship on the 7th PIIE Regional Congress. She also participated in SHS Flexsim Simulation Competition in Orlando, Florida and her team earned the 3rd place. After graduation, She plans to take the Certification Exam for Industrial Engineering and continue her path as an Industrial Engineer. 
